\title{
Ground Motion Analyses: OSSY (A High Explosive Experiment) and MERLIIN (A Nuclear Event)
}

\author{
R. P. Swift
}

October 1991

This is an informal report intended primarily for internal or limited external distribution. The opinions and conclusions stated are those of the author and may or may not be those of the Laboratory.

Work performed under the auspices of the L.S. Department of Energy by the Lawrence Livermore National Laboratory under Contract W-7405-Eng-48. 


\section{DISCLAIMER}

This document was prepared as an acccount of work sponsored by an agency of the United States Government. Neither the United States Government nor the University of California nor any of their employees, makes any warranty, express or implied, or assumes any legal liabih iy or responsibility for the aczuracy, completeness, or usefulness of any information, apparatus, product, or process disclosed, or represents that its use would not infringe privately own rights. Reference herein to any specific commercial products, process, or service by trade name, trademark, manufacturer, or otherwise, does not necessarily constitute or imply its endorsement, recommendation, or favoring by the United States Government or the University of California. The views and opinions of authors expressed herein do not necessarily state or reflect those of the United States Government or the University of California, and shall not be used for advertising or product endorsement pirposes.

This report has been reproduced directly from the best available copy.

Available to DOE and DOE contractors from the Office of Scientific and Technical Information P.O. Box 62, Oak Ridge, TN 37831

Prices : vailable from (615) 576-8401, FTS 626-8401

Available to the public rrom the National Technical Information Service

U.S. Department of Commerce 5285 Port Royal Rd., Springfield, VA 22161 


\section{Contents}

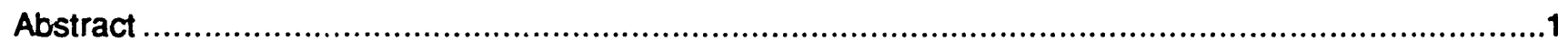

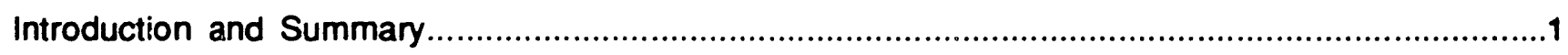

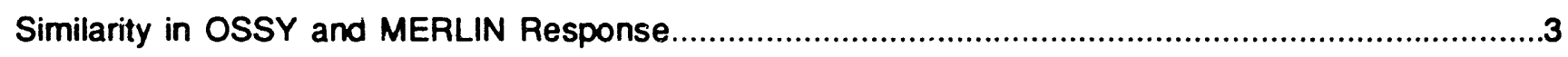

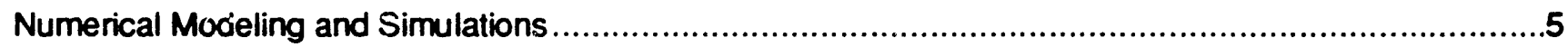

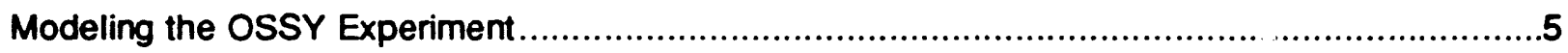

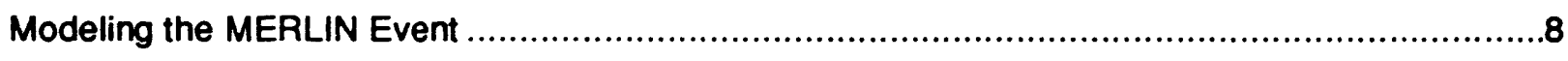

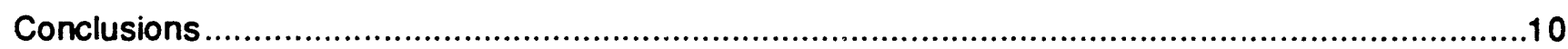

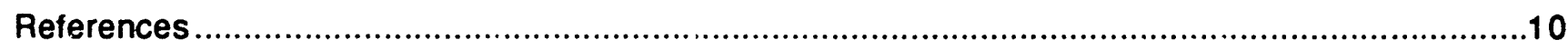

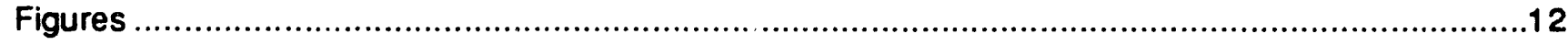

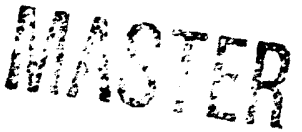




\title{
Ground Motion Analyses: OSSY (A High Explosive Experiment) and MERLIN (A Nuclear Event)
}

\begin{abstract}
We have analyzed recorded data and conducted numerical simulations of the seismic-calibration high explosive experiment OSSY and of the undergrc:ind nuclear event MERLIN to determine if there is any physical correlation in their ground motion response. Waveforms recorded on OSSY and MERLIN show a distinct similarity in the form of a dual-pulse structure, with the second pulse as large or larger than the first pulse. Results from 1D and 2D simulations show that there is no correlation. The dual-pulse structure for OSSY can best be accounted for by a dilatancy feature resulting from pore recovery during unloading. There is also a notable influence on the pulse shape caused by the large length-to-diameter ratio of the high explosive charge. The dual-pulse structure recorded in MERLIN is most likely due to refraction from a higher-impedance layer about $60 \mathrm{~m}$ below the workpoint.
\end{abstract}

\section{Introduction And Summary}

An accurate estimate of the yield for an underground nuclear explosion, based on seismic data, requires knowledge of how the near-field inelastic behavior can influence the characteristics of the explosion-induced seismic wave. Small high explosive (HE) charges detonated in an emplacement hole prior to a nuclear explosion provide a way to calibrate the seismic character of a particular site and to thereby facilitate determining the seismic yield. Using HE has an advantage over other seismic source generators, such as the airgun or vibroseis methods, because it can compact irreversibly some of the surrounding material in much the same manner that a nuclear explosion does, thereby providing a more complete calibration.

The On Site Seismic Yield experiment, OSSY, ${ }^{1}$ was performed to investigate the viability of a HE technique to help estimate the yield of nuclear explosions. Data from the OSSY experiment show dualpulse particle velocity waveforms in the near-and far-field with the amplitude of the second pulse larger than the first pulse. These waveforms are quite similar in structure to some horizontal waveforms obtained along the workpoint (WP) level for the nuclear event MERLIN. ${ }^{2}$ To gain some insight as to why these dualpulse features cccur, and if there is any correlative mechanism between the HE and nuclear cases, we examine how the character of the explosion-induced far-field response is affected by (1) certain features of inelastic rock/soil constitutive models apolied in the near-field region and (2) geology (e.g., layering) in the vicinity of the explosion. We accomplish this with brief analyses of the data from the HE OSSY 
experiment and the MERLIN event, and with numerical simulations of both using the finite element code KDYNA. $^{3}$

OSSY, conducted in September 1989 in hole UE-10ITS \#3, used C4 HE on four independent downhole charge strings. Each charge string consisted of three pairs of 10-pound and 100-pound charges. The two middle strings had downhole accelerometer gauges to record data in the vicinity of the charges. Although the pulse shapes are similar for both strings, a large variation in their amplitude from one string to another is mainly attributed to borehole sloughing in the gauge array region of the upper string. The time-of-arrival (TOA) and pulse amplitude data from this charge string indicate that the excess grout poured in the sloughy region of the borehole probably failed to bond the gauge package adequately to the surrounding medium. The result of this could have provided direct coupling via the grout for the close-in charge pair only $1 \mathrm{~m}$ away, while the response from the two distant charge pairs was decoupled from the gauge package. Data also indicate considerable influence on the close-in waveforms for the 100-pound charges (extending to about $8 \mathrm{~m}$ ) that is most likely due to the charge configuration and emplacement. To investigate how the recorded waveforms could have possibly resulted, we performed $1 D$ and $2 D$ simulations to examine the effects of material properties, charge canister configuration, and layering. Earlier, Maxwell ${ }^{4}$ had found that a pore recovery feature based on dilatancy during unloading led to a second pulse in the calculated OSSY response. Our simulations show the following: (1) a dilatant mechanism associated with pore recovery during unloading gives reasonable calculated agreement with the observed second pulse feature and needs only to be active in the vicinity of the cavity to have a pronounced effect, (2) the large length-to-diameter charge ratio of 8 affects the calculated up-axis response, and (3) layering influences the response, but only to a minor degree in comparison to the effects of dilatancy and charge configuration.

The MERLIN event had a 10-kt yield and was conducted in hole U3ct, at a depth-of-burial of 296 $\mathrm{m}$, on February 16, 1965. A unique aspect of MERLIN was the horizontal ground motion gauge array at the WP level, combined with a geology reported to be quite uniform and uncomplicated by layering or any nearby structure above the WP or in the horizontal directions. The data obtained by Perret ${ }^{2}$ from the horizontal array and two vertical gauge arrays in nearby satellite holes were of exceptional quality. The TOA from the far-range horizontal waveforms suggested that a higher-impedance material interface may exist somewhere between 40 to $70 \mathrm{~m}$ below shot level. The existence of a layer in this region could affect the shot-level response more than reflections from the ground surface. The shot-level waveforms show a dual-pulse structure developing beyond the $200-\mathrm{m}$ range, and $2 D$ simulations show that a layer $60 \mathrm{~m}$ below the WP can induce a dual-pulse response beyond this range. We also found that the dilatant modeling feature that had a major effect on the calculated OSSY response has only a slight influence on the calculated MERLIN response. Therefore, it appears that any similarity between the OSSY and MERLIN responses is merely coincidental. 


\section{SImilarity in OSSY and MERLIN Response}

The basic objective of the OSSY experiment was to assess the viability of using small HE charges to generate a seismic wave calibration of a particular site prior to an underground nuclear explosion; this would facilitate estimating the seismic yield of the explosion. It was conducted in September 1989 in hole UE-10ITS \#3 with four independent charge strings of C4 HE over a depth interval from $610 \mathrm{~m}$ up to $90 \mathrm{~m}$. Each charge string consisted of three pairs of 10- and 100-pound charges spaced about $40 \mathrm{~m}$ apart over a 90-m interval. Separation distance between the 10- and 100-pound charges in each pair was about $8.7 \mathrm{~m}$. Three-component seismic receivers were arrayed at various surface locations about the hole. $A$ discussion of the data from these is given in Ref. 5. The data we are addressing here come from the two middle charge strings that had 14 accelerometer gauge arrays spanning a distance of $11 \mathrm{~m}$ and starting about $1.36 \mathrm{~m}$ above the six-shot charge string. These gauges recorded the near- and medium-field response from the six shots, detonated in sequence, from the deepest to the shallowest.

A geologic cross-section schematic of the two charge strings with downhole gauges is shown in Fig. 1. The lower string contained shots 7 thru 12 and the upper string contained shots 13 thru 18 . Note that the even shot numbers correspond to the 100-pound charges and the odd numbers to the 10pound charges. All these shots were within the tuff units with the upper string gauge array being near an alluvium interface located at $229 \mathrm{~m}$ depth. There was considerable sloughing of the hole in this region, which had a pronounced effect on the response for shots 13-18. Though an attempt was made to couple the sloughy region to the charges with an excess amount of grout, the data indicate that a good coupling was not achieved. The depth versus $T A^{6}$ of the response for both strings of shots, shown in Fig. 2, shows a fairly consistent behavior for the deeper siring but a rather erratic behavior for the upper string near the alluvium interface.

In Fig. 3, the sonic speed associated with the TOA is superimposed with well log data from Ref. 7. The large differences between the Dhal and vibroseis data at depths of about $220 \mathrm{~m}$ to $300 \mathrm{~m}$ are also indicative that this portion of the hole is weak and unstable. ${ }^{8}$ The high sound speed associated with shots 17 and 18, closest to the gauges, is characteristic of the emplacement grout and indicates a possible direct coupling of 'this charge pair to the gauges via the grout. The rather disjointed TOA behavior, and its average low sound speed associated with shots 13-16, indicate that the medium was not well coupled either to the charges or to the gauge package or both. The poor coupling is further supported by the fact that the amplitudes of the response in the upper charge string, shots 13-16, are more than an order of magnitude lower than their counterparts in the lower string, shots 7-10 (see Fig. 4). It is of interest to note that although these upper-charge-string pulse amplitudes are lower, they still exhibit a second pulse larger than the first in much the same way as the better-coupled response from the lower string. Because of the above-mentioned emplacement and borehole sloughing problems our modeling effort focuses on the lower charge string data, primarily for the 100-pound shots 12 and 10. 
Particle velocity waveforms from some of the same gauges recording shots 12 and 10 are given in Figs. 5 and 6 . The data obtained for the close-in gauges on shot 12 (Figs. 5a-d) are probably affected by their close proximity to the large length-to-diameter charge, and are quite different from the dual pulse response beyond $8 \mathrm{~m}$ (Figs. $5 \mathrm{e}-\mathrm{f}$ ). Beyond $8 \mathrm{~m}$ in shot 12 the evolving response is qualitatively similar to the dual-pulse structure observed in shot 10 (Fig. 6) and in the other shots on this siring, which, because of charge size and/or distance from the gauge array, are of lower amplitude. Response similar to that of shot 12 was also obtained on shot 18, the shot closest to the gauge package for charge string 3 .

A similar dual-pulse structure was observed in ground motion measurements for the MERLIN event. ${ }^{2}$ Ground motion measurements were made at the WP level in five drill holes located at ranges 107 $\mathrm{m}, 213 \mathrm{~m}, 335 \mathrm{~m}, 488 \mathrm{~m}$, and $763 \mathrm{~m}$, respectively, with the gauges in these holes oriented to respond to radial motion. Two vertical arrays of gauges were located in drill holes at distances of $15.24 \mathrm{~m}$ and $45.7 \mathrm{~m}$ from the emplacement hole as wf!! as several surface stations. Figure 7 shows the locations of the stations on a vertical plane through the WP. The geology was reported to be a very uniform unit of alluvium with no nearby structures in the horizontal or vertical direction and a possible tuff layer that was estimated to exist somewhere between 40 and $70 \mathrm{~m}$ below the WP. The data obtained were of high quality, with only the gauge closest to the source failing immediately after the shock peak arrived. The WP-level response is our chief concern here, as the the four further waveforms in Fig. 8 exhibit a dualpulse structure with the second pulse becoming larger in amplitude than the first, which is qualitatively similar to the OSSY data. The distance of the WP-level gauges to the ground surface, combined with the sound speed for the alluvium (1200 to $1700 \mathrm{~m} / \mathrm{s}$ ) precludes this surface from being the cause of the second pulse. However, the TOA data given in Fig. 9 show a sound speed increase from $1533 \mathrm{~m} / \mathrm{s}$ to $2110 \mathrm{~m} / \mathrm{s}$ beyond the 213-m station. This implies refraction of the ground shock through the deeper higher-velocity tuff material, with the resulting interaction possibly inducing the second pulse in the horizontal waveforms.

It is of particular interest to try to understand the cause of the dual-pulse structure in these waveforms because it may represent an identification feature that could be useiu! in understanding seismic data in relation to close-in ground motion response. The questions that arise from this brief analysis of the OSSY HE and the MERLIN nuclear-explosion ground motion data are as follows: What is/are the responsible mechanism/s for the dual-pulse structures? Are the pulse structures physically correlated? What is the influence of geologic layering interacting with the HE- and nuclear-explosioninduced ground shock waves? 


\section{Numerical Modeling and Simulations}

To examine the above questions concerning the dual-pulse structure observed on OSSY and MERLIN we performed $1 D$ and $2 D$ simulations using the finite-element code KDYNA. Because of the considerable uncertainties associated with modeling ground motion measurements in a geologic field environment, our goal was not to replicate the waveforms in an accurate quantitative manner, but simply to address the dual-pulse structure qualitatively by assessing material property effects for a simple constitutive model. We first performed 1D calculations of the OSSY experiment to ascertain what constitutive features provide a representative dual-pulse response. $2 \mathrm{D}$ simulations were then performed to address the canister and emplacement effects and the influence of layering. In a similar manner, we then conducted 1D and 2D simulations for the MERLIN event. Details and results of the calculations are given below.

\section{Modeling the OSSY Experiment}

The constitutive model and equation-of-states (EOS) used in the KDYNA simulations of the OSSY experiment were the JWL EOS 2 for the HE C4, and material model 23 and EOS 11 for the geologic material and grout. ${ }^{3}$ The steel casing for the explosive was found to have little effect on the calculated ground motion and was ignored in the following calculations. The geologic material models are based on concepts of pore collapse, ${ }^{9}$ yield behavior, ${ }^{10}$ and tensile failure. ${ }^{11}$ The volumetric and seismic elastic properties for the region around shot 12, located right near the Paintbrush/Wahmonie tuff interface at a depth of $359.2 \mathrm{~m}$, are based on the density logs 12 and the seismic velocity profile. ${ }^{7}$ Nominally these properties are bulk density of $1570 \mathrm{~kg} / \mathrm{m}^{3}$, total porosity of $46 \%$, water content of $11 \%$ by weight, sound speed of $1777 \mathrm{~m} / \mathrm{s}$, and Poisson's ratio of 0.25 .

Figure 10 shows the pressure-excess compression and the tri-axial compression strength behaviors for the tuif and grout used in the simulations. Three variations for the unloading portion of the pressure-excess compression curve (Fig. 10a) are used in the 1D calculations. One is unloading with constant porosity and the other two are unloading with different degrees of elastic pore recovery. In Fig. 11, the calculated responses for the three different unloading conditions (dashed lines) are compared with measured data (solid lines) at $9.5 \mathrm{~m}$ for shot 12 and at $41.86 \mathrm{~m}$ for shot 10 , respectively. While constant porosity in!?sading does not induce a pronounced second pulse, the pore recovery unloading feature causes a significant second pulse, which is highly sensitive to the character of the dilatancy. The dilatancy effect, in addition to inducing a second pulse, causes broadening of the pulse, as observed in Fig. 12, which compares the response calculated for the different unloading cases. It is observed that a lower stress onset for dilatancy appears to cause more broadening of the wave and enhancement of the second pulse. 
We allowed the dilatant pore recovery effect to act over the entire grid in the above calculations. Figure 13 compares the calculated response for the case when the region of dilatancy is restricted to the nonlinear portion of the problem (i.e., over $1 \mathrm{~m}$ to $2 \mathrm{~m}$ beyond the cavity) with the response when dilatancy acts over the entire grid. For a $1-\mathrm{m}$ restriction, the first pulse is narrower and the second pulse is less pronounced in comparison with dilatancy acting over the entire region, but still more apparent than for no dilatancy. For a 2-m restriction, only the second pulse is slightly more narrow than that with dilatancy acting everywhere. For the present constitutive model, no other material parameter, within expected bounds for the OSSY materials, has as much of an effect in generating a dual-pulse structure as has the dilatancy feature. However, effects of the charge configuration (i.e., length-to-diameter ratio of eight), the grout emplacement of the charge, the grout emplacement and epoxy packaging of the gauges, the geologic layering, and in situ stress conditions are all considered to play some role on the recorded response.

To define how significant charge geometry (length-to-diameter ratio of 8 ) and grout emplacement effects are, we performed $2 D$ axisymmetric simulations of shots 10 and 12 with uniform geology to separate out the influence of layering. The calculated $2 D$ response (waist and up-axis) for uniform geology with grout in the borehole is compared with the $1 \mathrm{D}$ response at $4 \mathrm{~m}$ and $9.5 \mathrm{~m}$ in Fig. 14. While the shape of the first pulse for the waist response is similar to the $1 \mathrm{D}$ response, but with a higher peak, the second pulse is very different. The up-axis response is more analogous to the $1 D$ response in the second pulse. Neither the waist nor the up-axis response has as large of a negative peak as the 1D case. Figure 15 shows that the up-axis response being sinusoidal is more representative of the recorded data. In a manner similar to the 1D calculated response, the effect of dilatancy as opposed to no dilatancy, also shown in Fig. 15, induces a significant second pulse that is more representative of the recorded response. A comparison of the case for grout with that for the grout replaced by the natural tuff medium is shown in Fig. 16. The influence of the grout on the close-in response is apparent in Figs. 16a and b, with the up-axis response having a higher peak when grout is omitted while the opposite occurs for the waist response. However, at distances beyond about $2.5 \mathrm{~m}$ the up-axis and waist responses with and without grout, shown at $9.5 \mathrm{~m}$ in Figs. $16 \mathrm{c}$ and $\mathrm{d}$, are very close. Note again that the waist response is similar to the $1 \mathrm{D}$ behavior, and its later TOA at stations close to the charge (Figs. 16b and d) is due to the stations being effectively farther from the charge than the corresponding up-axis stations.

The above $2 \mathrm{D}$ simulations indicate that the charge configu ation has considerably more influence on the pulse shape than does the grout emplacement. The differences between the calculated up-axis response, which is qualitatively like the recorded up-axis waveforms, and the waist response, which is similar to the 1D spherical behavior, reflects the effect of the large length-to-diarieter ratio of the cr arge. For a length-to-diameter ratio of 1 (Fig. 17) the calculated responses for the up-axis and the waist are nearly identical and have the character of the $1 D$ spherical response. 
It can be surmised that the spectral content from the meaured close-in up-axis response may be affected by the charge configuration; however, it is doubtful that the effectiveness of OSSY as a seismic tool for calibrating an explosion site will be deterred. This is because the technique described in Ref. 1 uses a Green's function approach that removes the influence of the propagation path between the source and the seismic stations; i.e., the nuclear explosion is proportional not to the absolute value of the seismic spectrum, but to the ratio of the long-period spectral levels of the nuclear source to the HE source. Other uncertainties that may adversely affect OSSY are local geology and the variability of source coupling. We address the influence of the local geology on the close-in response below. We do not address source coupling here, but suffice it to mention that decoupling of the gauge package in charge string 3 , as previously discussed, gave a response an order of magnitude less than that for charge string 2 . If the source was similarly decoupled, a similar reduction in response amplitude would be expexted.

The influence of layering was examined in $2 \mathrm{D}$ simulations using the configuration shown in Fig. 18. To enhance the effect of the 18-m-thick Wahmonie tuff layer just below the gauge array and the shot 12 charge, it was modeled as being less compressive but stronger than the Paintbrush and Belted tuff units, which were assumed to be the same. A gas-filled porosity of about $6 \%$ with a sound speed of $2344 \mathrm{~m} / \mathrm{s}$ and maximum strength of about $30 \mathrm{MPa}$ was used for this layer. Figure 19 shows comparisons of the up-axis and waist responses at $4 \mathrm{~m}$ and $9.5 \mathrm{~m}$ for shot 12 in uniform and layered geologies and the up-axis response at $\mathbf{4 1 . 8 6} \mathrm{m}$ for shot 10. Very little difference is noted for the up-axis response (Figs. 19a and c), with the exception that layering causes a slight modification of the negative phase and the second pulse. The waist response differences (Figs. 19b and d) increase as the wave propagates outward. An earlier TOA occurs for the farther-out ranges because of the influence of the higher-sound-speed layer below the charge. The layering effect is more pronounced on the up-axis response for shot 10 , shown in Fig. 19e, providing an improved TOA and phasing of the calculated waveforms in comparison with data.

The order of the effect of layering on the calculated response is secondary to how the dilatancy feature affects the results. The trend of the calculated response in comparison with recorded data (that is, the first pulse being higher in magnitude and broader in wavelength while the second pulse is lower in magnitude) is consistent for both shots 10 and 12 simulations with and without layering. The reason for this can only be surmised as either a model deficiency, problems with experimental reproducibility as alluded to earlier in the discussion of the OSSY experiments, or both. The dilatancy feature mimicking pore collapse recovery was implemented in an ad hoc manner for these simulations. Another way to obtain pore recovery is through shear-induced dilatancy when the material is undergoing plastic yielding on the pressure-dependent port: un of the yield surface. Examination of the stress paths shows that such yielding is occurring during unl , ling out to about $2 \mathrm{~m}$ beyond the cavity and is an indication that shearinduced dilatant behavior would provide the same effect in the waveforms. Our present model is nonassociative and does not allow for dilatancy through shear yielding. It is not expected thai such a simple model can capture all the nuances of the recorded wavefoims. However, the fact that the dilatancy 
feature provides a dual-pulse waveform motivated us to use it to examine the MERLIN event's WP-level response to determine if there may be some correlation between MERLIN and OSSY.

\section{Modeling the MERLIN Event}

Modeling of the MERLIN event has also been carried out by Brunish and App. ${ }^{13}$ Their interest was in containment of low-yield events in porous alluvium and they focused mainly on the response between the WP and the surface. Our modeling effort here addresses the response recorded at the WP level, shown in Fig. 8. Physical and mechanical properties are based on geophysical logs run in the nearby hole U3kx and on laboratory measurements on in situ and reconstituted core samples from the MERLIN emplacement hole U3ct. ${ }^{14}$ The values we used are $1710 \mathrm{~kg} / \mathrm{m}^{3}$ for bulk density, $43 \%$ total porosity, $11 \%$ weight water content, 0.292 for Poisson's ratio, and $1415 \mathrm{~m} / \mathrm{s}$ for sound speed. The pressure-excess compression and strength behavior that provided our best agreement with the closest recorded response at $107 \mathrm{~m}$, again using model 23 and EOS $11,{ }^{3}$ are shown in Fig. 20. The initial pore crush-up is somewhat rounded with an onset starting at $2 \mathrm{MPa}$, and full removal of gas-filled porosity at 47.8 MPa. Although the total porosity of the MERLIN alluvium is nearly the same as the tuff in the OSSY experiment, its crush-up behavior and strength are considerably lower. The si:ength has an unconfined value of $0.01 \mathrm{MPa}$ and a maximum confined value of $10 \mathrm{MPa}$, which is consistent with data for water content $10-15 \%$. The three unloading variations shown for the alluvium are similar to those for the OSSY tuff, one with constant porosity and the other two with different rates of elastic pore recovery. The highpressure energy-dependent behavior of the alluvium was created from the above physical properties using the approach for geologic media in Ref. 15. The source is modeled as a 10-kt iron-gas sphere with a $0.98-\mathrm{m}$ radius and initial density of $1500 \mathrm{~kg} / \mathrm{m}^{3}$.

One-dimensional simulations are compared with the MERLIN WP-level response at ranges $107 \mathrm{~m}$, $213 \mathrm{~m}, 335 \mathrm{~m}, 448 \mathrm{~m}$, and $763 \mathrm{~m}$ in Figs. 21a-e for cases with and without dilatancy during unloading. The agreement wrih data is best achieved at the range of $107 \mathrm{~m}$ where the recorded response is probably least affected by a layer below the WP. The farther-out stations show very poor agreement with data. Note that the TOA for the farthest-out stations is noticeably slower than the recorded TOA. The case with dilatancy gives behavior similar to that calculated for the OSSY response (Fig. 11) but not to the same extent. The attenuation of the peak close in is retarded, hence the considerably higher value at range $107 \mathrm{~m}$. For the farther-out ranges the peaks have shifted to the rear of the first positive phase, being slightly higher for the dilatancy case, along with a broadening of the negative phase and a slightly higher peak in the second pulse. A comparison of the response for the three unloading conditions is shown in Fig. 22. Some pulse structure is formed in the first positive phase for the dilatancy $\mathrm{C}$ case but it does not enhance with range as the recorded response shows in Fig. 8 . In Fig. 23, a comparison is given for the response for dilatancy $D$ restricted to the nonlinear portion of the problem (i.e., about $100 \mathrm{~m}$ ) as opposed 
to it acting over the entire grid. Again, the trend of the differences is similar to that for OSSY, but to a lesser degree. Several parameter changes in material behavior such as strength, crush-up behavior, and Poisson's ratio were attempted in the 1D simulations; however, no better agreement could be obtained at station $107 \mathrm{~m}$ and the comparisons at the farther-out stations were similar to that above.

In the above comparisons it is noteworthy that the dilatancy feature that had a dominant influence on the calculated OSSY response has only a minor effect here. Although somewhat of a dual-pulse structure is obiained in these simulations, it is associated with the natural rebound of the cavity region, and is influenced only slightly by the pore recovery mechanism. The data indicate that the dual-pulse structure is forming in the positive phase of the response around $200 \mathrm{~m}$ and effectively increasing as the wave propagates outward. To understand how this can happen, we examine the effect of a layer below the WP on the calculated response in $2 \mathrm{D}$ simulations.

The configuration for the 2D axisymmetric simulations for MERLIN is shown in Fig. 24. We assume an alluvium-tuff interface to be located $60 \mathrm{~m}$ below the WP level. A total of 9000 elements with ratio zoning increases upward and downward are employed. The zoning in the outward direction in the vicinity of the WP level is sufficient to capture wave frequencies an order of magnitude higher than those of the recorded response. The nominal element size varied outward from $4 \mathrm{~m}$ at range $10-40 \mathrm{~m}$ at range $1200 \mathrm{~m}$. We modeled the tuff to be considerably stiffer and stronger than the alluvium, with two sets of properties - one being representative of a hard welded tuff, denoted as "hard tuff," and the other a competent but much soiter material, denoted as "soft tuff." The properties for the hard and soft tuff layers are, respectively, sound speed of 2650 and $2340 \mathrm{~m} / \mathrm{s}$, Poisson's ratio of 0.21 and 0.25 , porosity of 3.5 and $5.8 \%$, pore crush-up onset of 78.6 and $9.1 \mathrm{MPa}$, complete pore collapse pressure of 5 and $0.3 \mathrm{GPa}$, and unconfined compression strength of 64 and $30 \mathrm{MPa}$.

Comparisons of the 2D calculated response using the hard tuff and soft tuff layers with the recorded response are shown in Fig. 25. Noting that the influence of the layer on the waveforms is sensitive to its location, we see that the calculated response is qualitatively similar to the recorded response, with the soft tuff providing a somewhat better match than the hard tuff. The TOA of the 2D calculated waveforms agrees better with the data when layering is accounted for, again, that for the soft tutf layer being slightly closer than that for the hard tuff layer. The dual-pulse structure formed in the wave as it propagates outward is an induced modification of the positive phase of the first pulse caused by the effect of the layer below the WP. This is illustrated more clearly in Fig. 26, which compares the calculated response with the effect of layering with that for no layering (i.e., uniform geology).

The above results indicate that the MERLIN WP-level response was very likely influenced by a layer of a denser material below the WP. Logging from other nearby holes indicates that an alluvium-tuff interface should be slightly below the WP level, and the TOA data supports that a higher-impedance material could be somewhere between 40 and $70 \mathrm{~m}$ below the WP. Combining these observations with the result that the dilatancy reature has only a minimal effect on the calculated MERLIN response, it is 
surmised that there is no correlation between the dual-pulse structure responses observed for the MERLIN event and inose for the OSSY experiment.

\section{Conciusions}

We have conducted analyses and numerical simulations of the OSSY experiment, which used HE charges in hole UE-10 ITS \#3 containing different tuff rocks, and the WP-level response of the MERLIN event, a 10-kt nuclear explosion in alluvium. The results of this effort indicate that there is no physical correlation between the responses recorded in OSSY and MERLIN and that any similarity in the dual-pulse structure observed in their waveforms is strictly coincidental.

A large variation in the amplitude of the OSSY response from charge string 3 to that of charge string 2 is observed, and is attributed to borehole sloughing in the vicinity of the gauge package for charge string 3 and a possible failure of the grout poured in this region to propertly couple the gauge package so the medium. We find that the OSSY response, which is from accelerometers located up-axis to the charges, may be significantly influenced by the large !ength-to-diameter charge ratio and that the grout emplacement of the charge and the geologic layering play only minor roles in shaping the response. We find that the second pulse feature in the response can be best accounted for by applying a dilatancy feature that allows for pore recovery during unloading and that $c$ ther material $\mu^{-1}$ perty variations do not provide any contribution to the formation of a second pulse.

In our simulations of the MERLIN WP-level response, we find that a higher-impedance layer below the WP is most likely responsible for the dual-pulse structure observed in the recorded waveforms. This is supported by the TOA data, which show a considerably higher arrival speed at the farther-out stations, indicating refraction effects from a harder layer below the WP. Our modeling shows that the dilatancy feature, which has a dominiant effect on the OSSY response, gives only a slight perturbation to the waveform and that it does not provide any significant contribution to a second pulse. We surmise that the insensitivity to dilatant unloading is probably due to the very low pore collapse threshold and relative ease

r compaction of the alluvium reidtive to the more stiff fuif material for OSSY.

\section{References}

1. M. Denny and S. Taylor, "On-Site Seismic Yield Estimation," Memorandum SAG 89-9, Lawrence Livermore National Laboratory, Livermore, CA (April 27, 1989).

2. W. R. Perret, Free-Field and Surface Motion From a Nuclear Explosion in Alluvium: Merlin Event, Sandia National Laboratory, Albuquerque, NM, SC-RR-69-334 (November 1971). 
3. J. L. Levatin, A. V. Attia, and J. O. Hallquist, KDYNA User's Manual, Lawrence Livermore National Laboratory, Livermore, CA, UCRL-ID-106104 (September 28, 1990).

4. D. Maxwell, private communication, November 1990.

5. L. R. Johnson and T. V. McEvilly, OSSY Source Characterization-Summary Report, Department of Geology and Geophysics, University of California, and Center for Computational Seismology, Lawrence Berkeley Laboratory (September 1990).

6. M. Denny, private communication, November 1990.

7. T. M. Dailey, T. V. McEvilly, and A. Michelini, VSP Site Characterization at NTS-Summary Report, Certer for Computational Seismology, Lawrence Berkeley Laboratory (August 1990).

8. J. T. Rambo and R. P. Switt, "A Possible Relation Between Sonic Velocity Measured at the Edge of a Large Borehole and Shear Failure," Proceedings of the 4th Symposium on Containment of Underground Nuclear Explosions, Colorado Springs, CO, C. W. Olsen, Ed., Lawrence Livermore National Laboratory, Livermore, CA, CONF-870961 (September 1987).

9. S. C. Cowin and J. M. Carroll, The Effects of Voids on Material Deformation, American Society of Mechanical Engineers, New York, NY, AMD-16 (1976).

10. M. B. Rubin, A Simple and Convenient Isotropic Failure Surface, Lawrence Livermore National Laboratory, Livermore, CA, UCRL-102556 (1989).

11. M. B. Rubin and A. V. Attia, A Continuum Tensile Failure Model With Friction, Lawrence Livermore National Laboratory, Livermore, CA, UCRL-ID-104759 (August 1990).

12. G. Pawloski, Gas Porosity from U10ITS \#3, Nuclear Test Containment Program Report GAP90-03, Earth Sciences Department, Lawrence Livermore National Laboratory, Livermore, CA (December 5 , 1990).

13. W. M. Brunish and F. N. App, "Modeling of Merlin Alluvium," Proceedings of the 5th Symposium on Containment of Underground Nuclear Explosions, Santa Barbara, CA, C. W. Olsen, Ed., Lawrence Livermore National Laboratory, Livermore, CA, CONF-8909163 (September 1989).

14. B. P. Bonner, A. E. Abey, H. C. Heard, and R. N. Schock, High Pressure Mechanical Properties of MERLIN Alluvium, Lawrence Livermore National Laboratory, Livermore, CA, UCRL-51252 (July 1972).

15. T. R. Butkovich, B. Moran, and D. E. Burton, A Model for Calculating Shock Loading and Release Paths for Multicomponent Geologic Media, Lawrence Livel'more National Laboratory, Livermore, CA, UCRL-53178 (July 1981). 


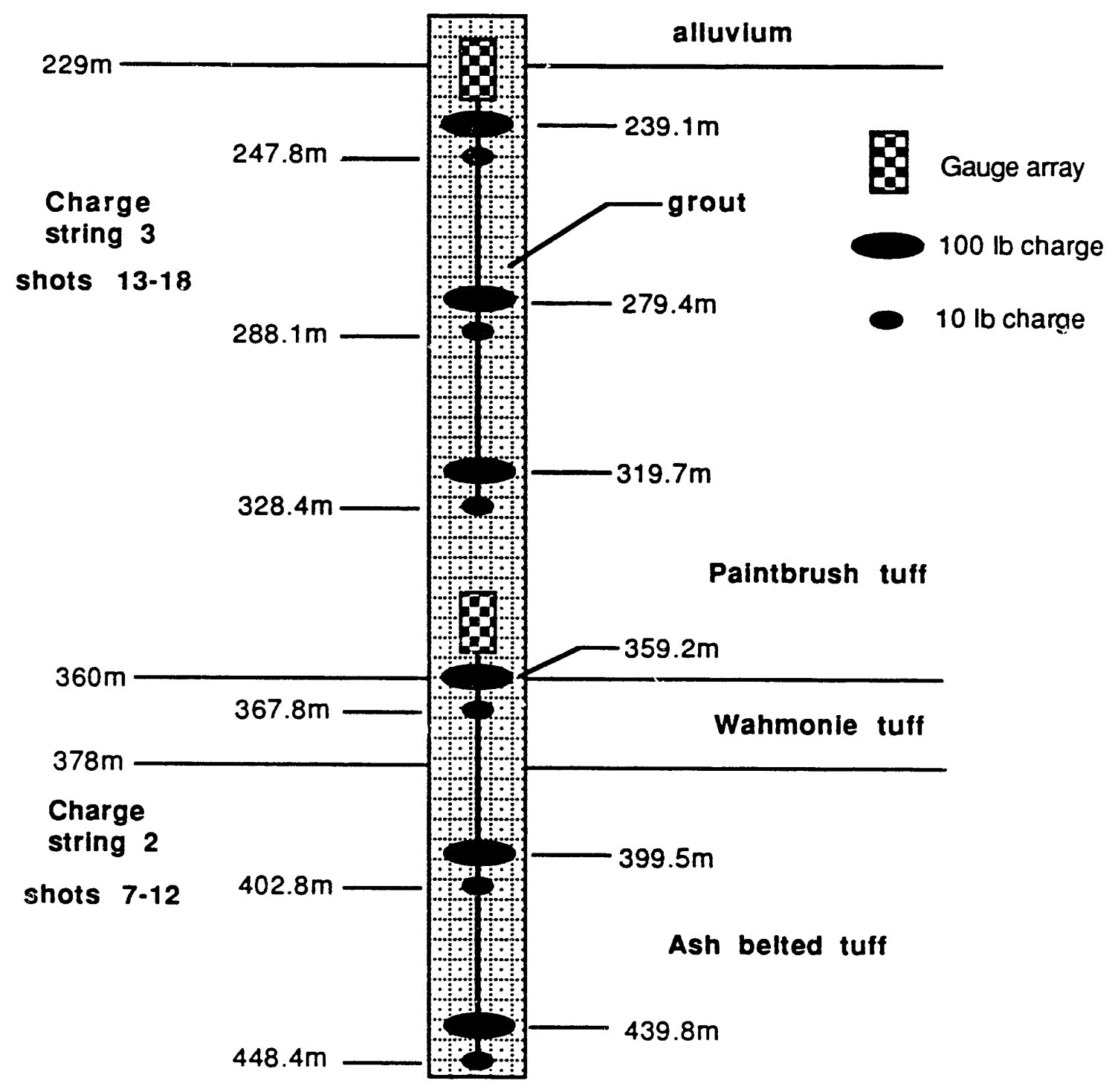

Figure 1. Schematic of OSSY charge strings 2 and 3 in hole UE-10 ITS \# 3. 


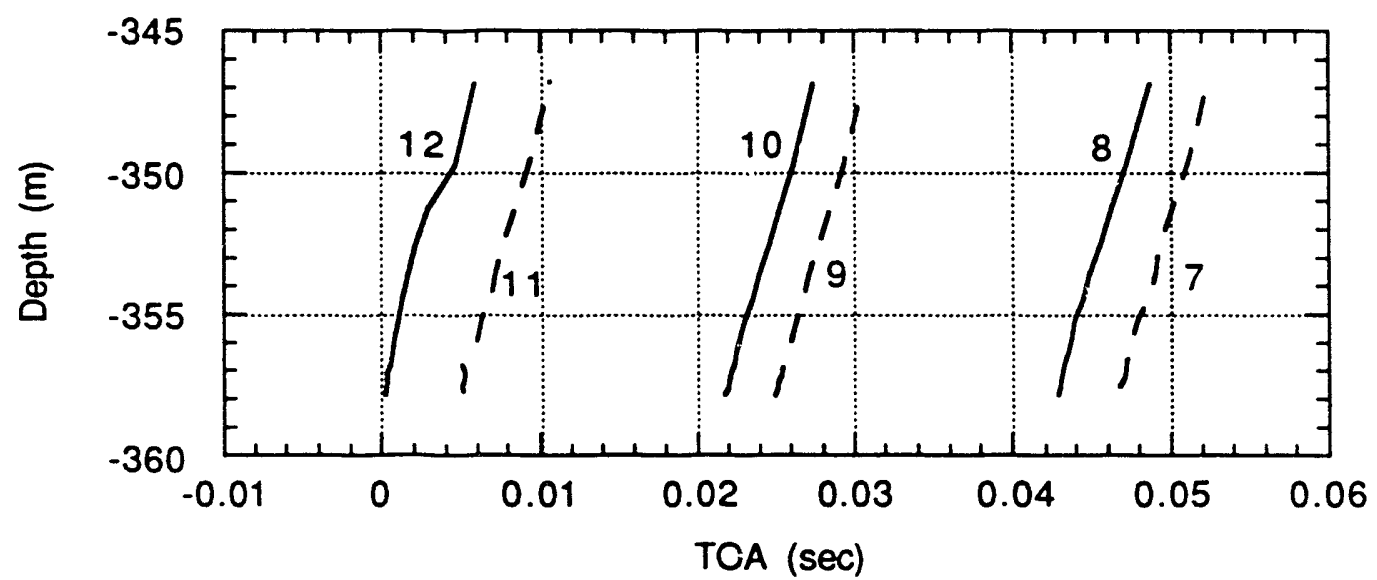

a. Charge string 3 . shots 13 to 18

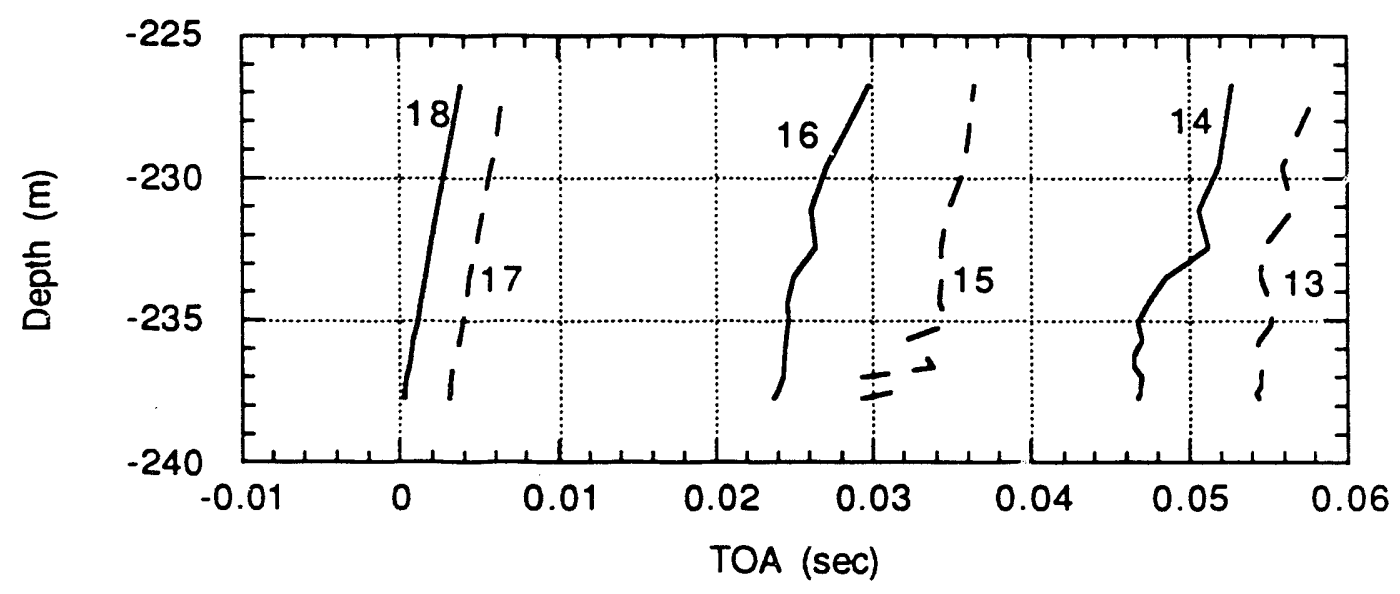

b. Charge string 2, shots 7 to 12

Figure 2. Depth versus TOA at gauge locations for charge strings 2 and 3 : Solid -100 pound shots, Dash -10 pound shots. 


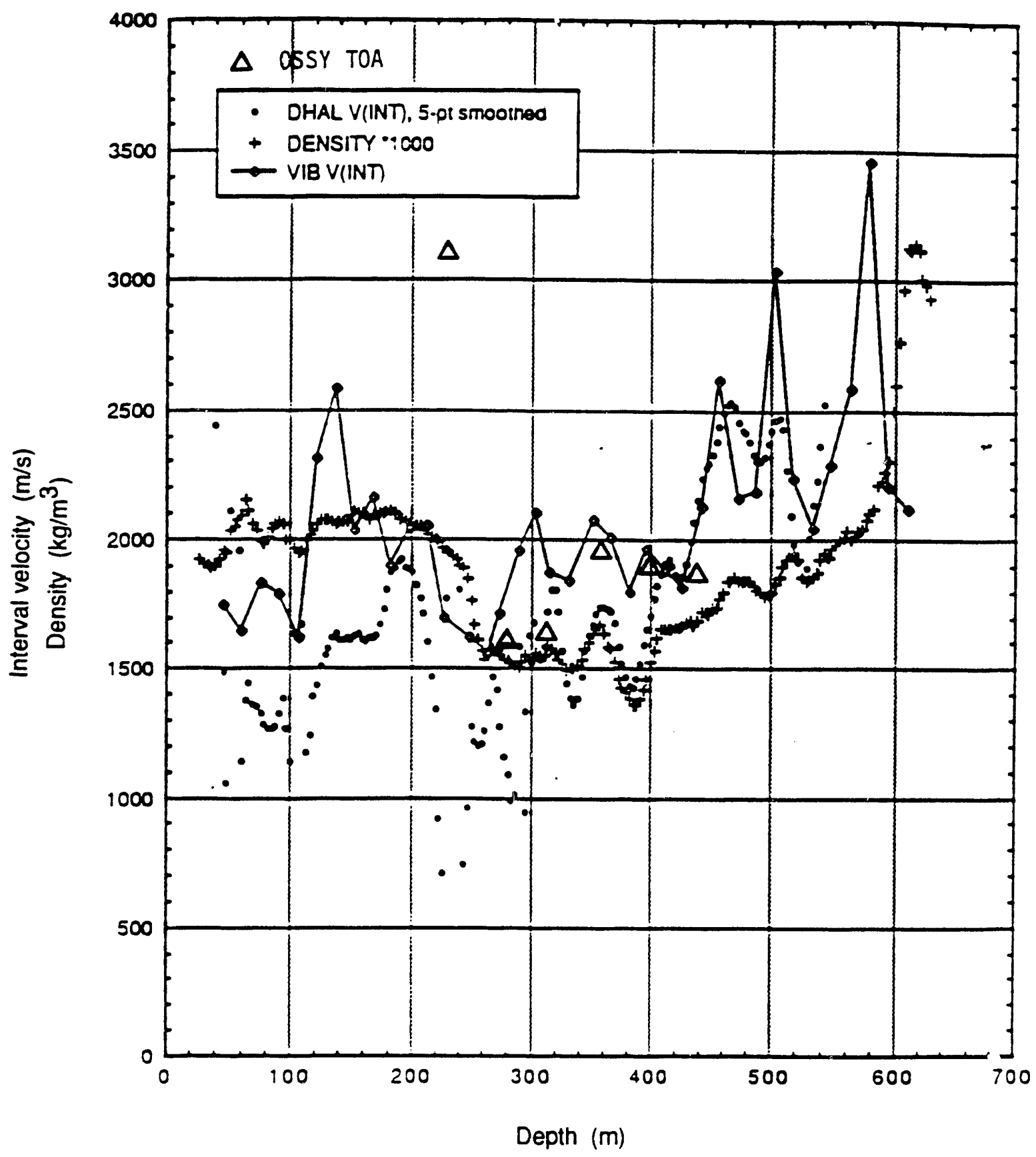

Figure 3. Well log data for hole UE-10 ITS \#3 from Ref. 7 with wave speed from OSSY TOA ground motion data for shots $7-12(\Delta)$ added. 


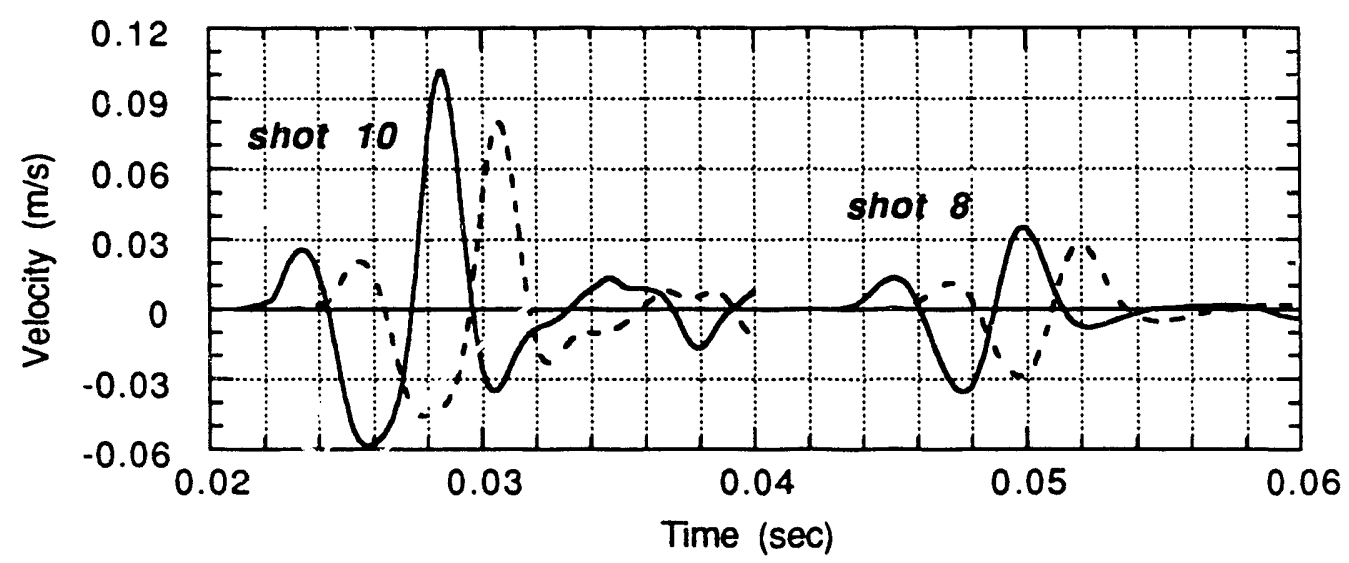

a. Shots 8 \&10, Solid - gauge 2, Dash - gauge 10

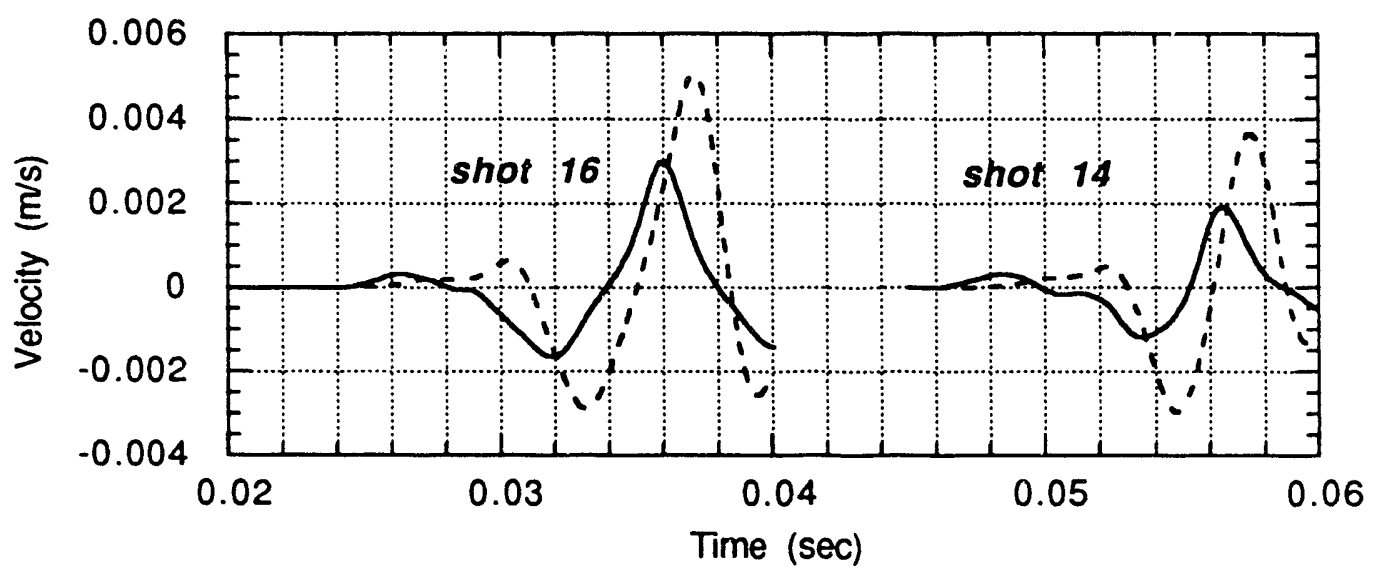

b. Shots 14\&16, Solid - gauge 2, Dash - gauge 10

Figure 4. Particle velocity records from OSSY shots. (a) shots 8 and10 at depths $439.8 \mathrm{~m}$ and $399.5 \mathrm{~m}$ and (b) shots 14 and 16 at depths $319.7 \mathrm{~m}$ and $279.4 \mathrm{~m}$. 


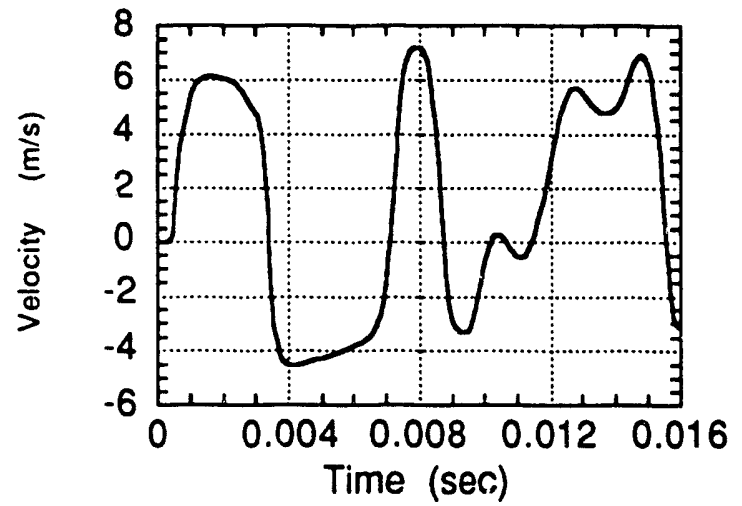

a. Gauge 2, Distance $=1.56 \mathrm{~m}$

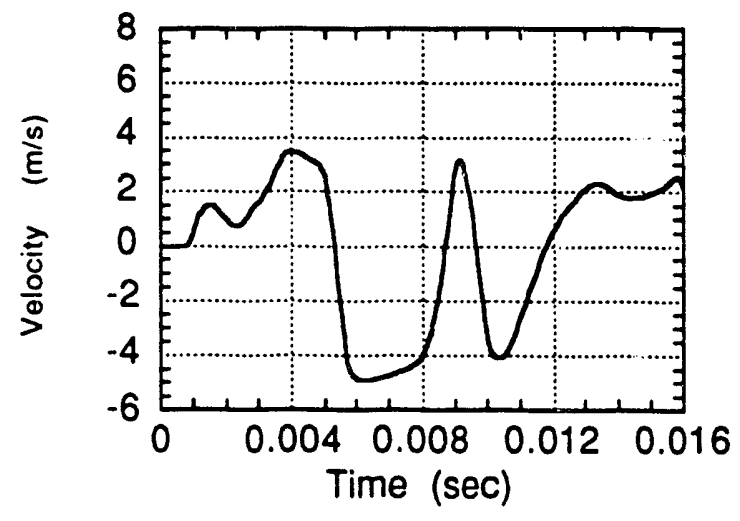

b. Gauge 6, Distance $=2.875 \mathrm{~m}$

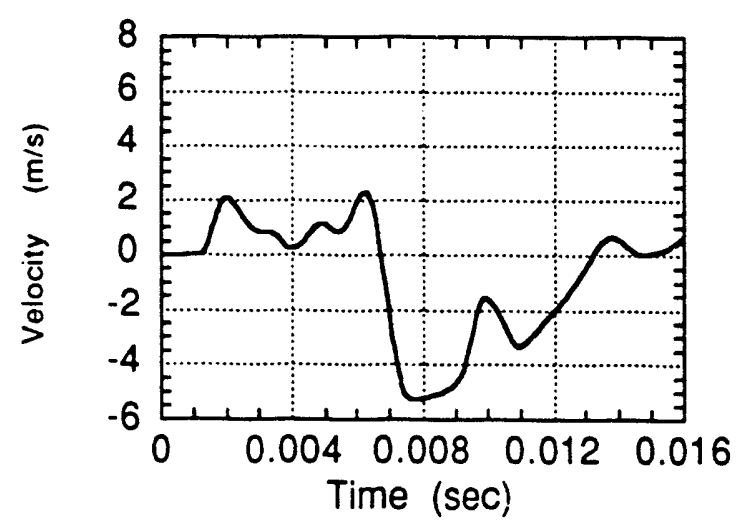

c. Gauge 8 , Distance $=4.000 \mathrm{~m}$

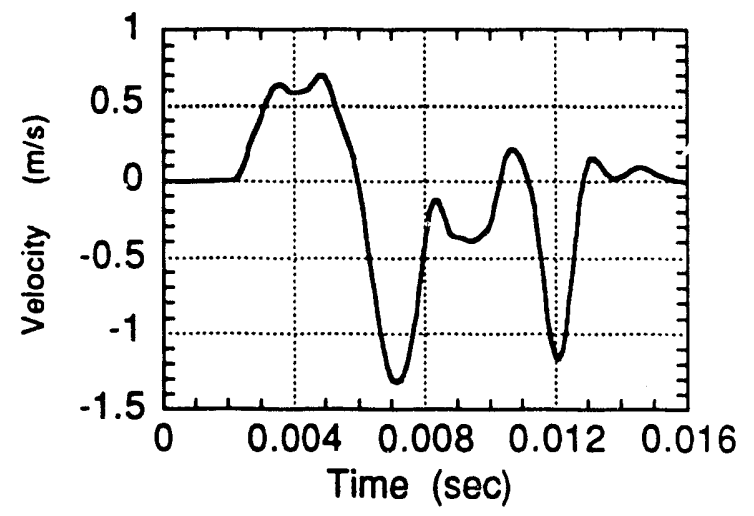

d. Gauge 11, Distance $=6.685 \mathrm{~m}$

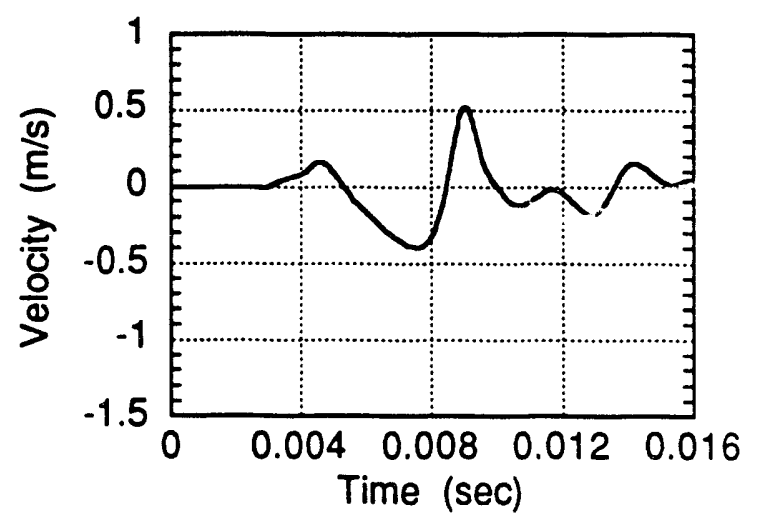

e. Gauge 12 , Distance $=7.966 \mathrm{~m}$

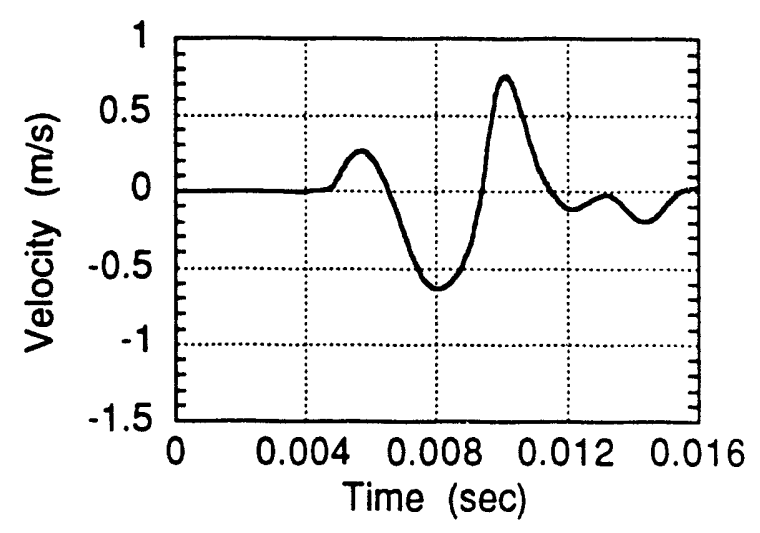

f. Gauge 13, Distance $=9.500 \mathrm{~m}$

Figure 5. Particle velocity waveforms from OSSY shot 12. 

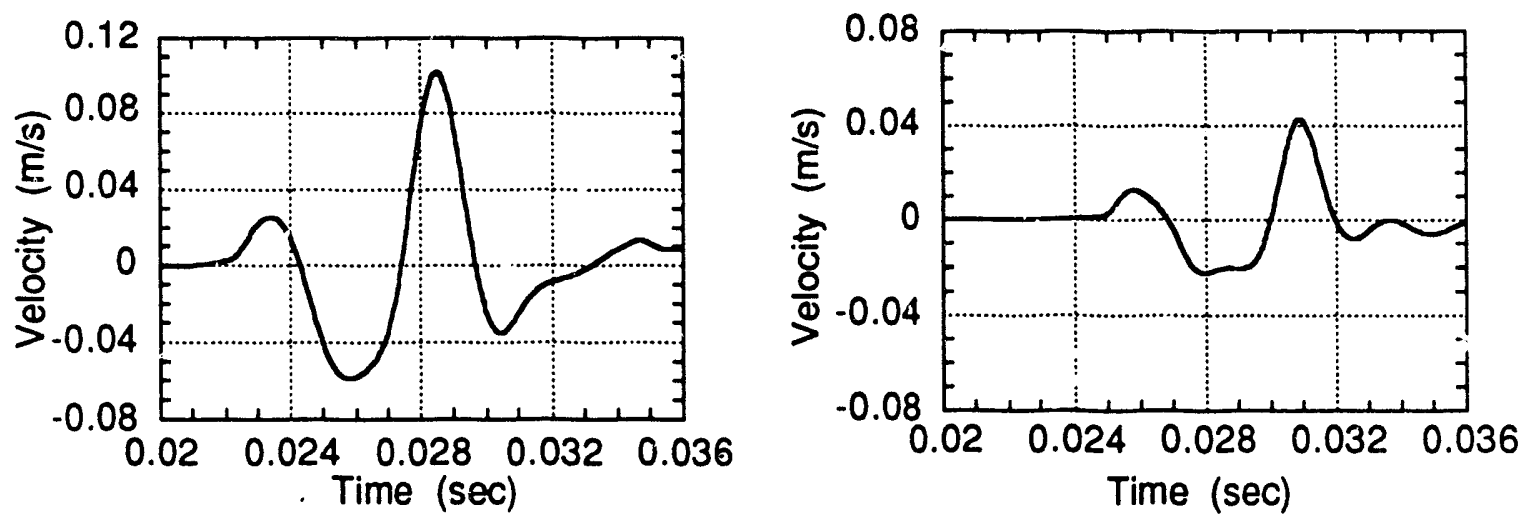

a. Gauge 2, Distance $=41.86 \mathrm{~m}$
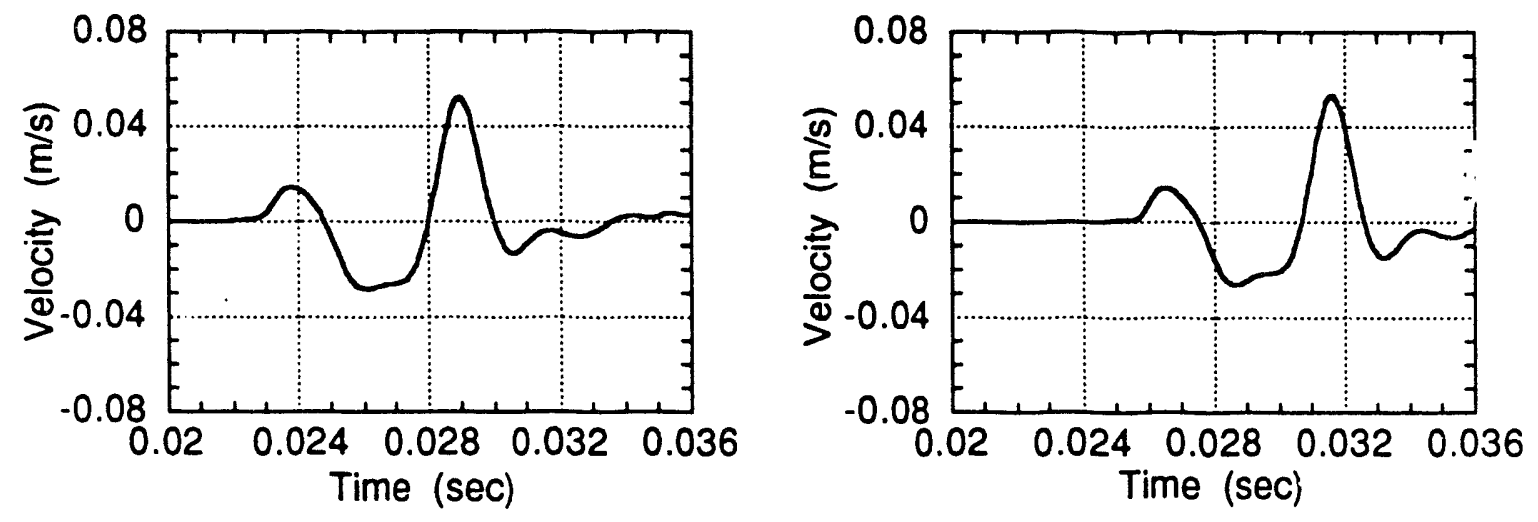

b. Gauge 6, Distance $=43.18 \mathrm{~m}$
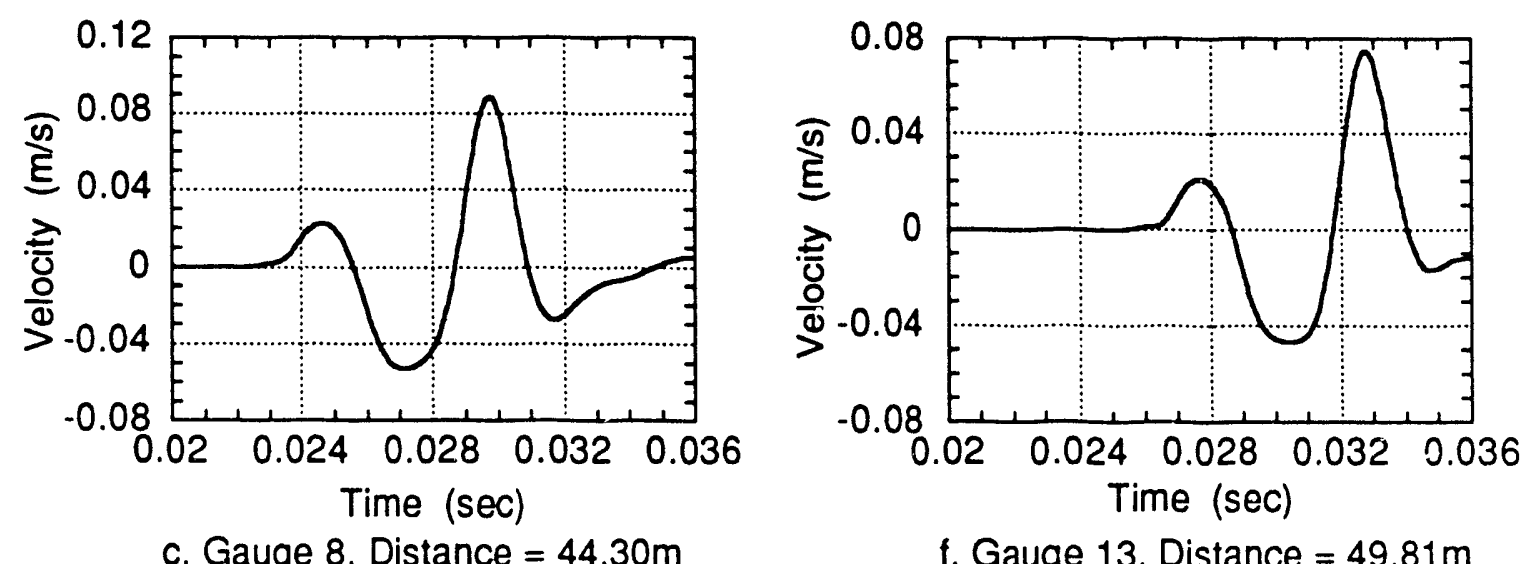

f. Gauge 13, Distance $=49.81 \mathrm{~m}$

Figure 6. Particle velocity waveforms from OSSY shot 10. 


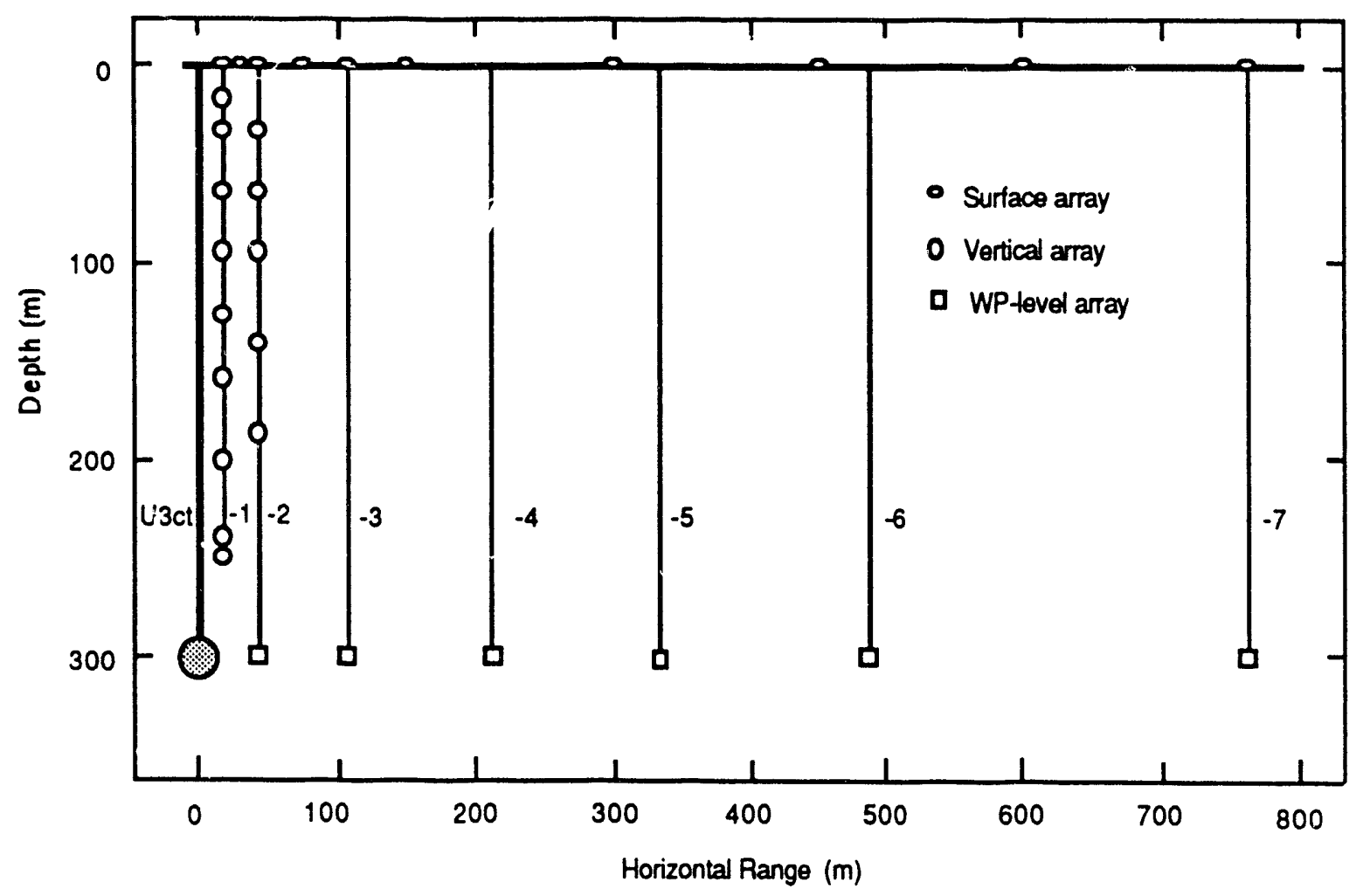

Figure 7. Configuration of ground motion instrumentation arrays for the MERLIN event. 


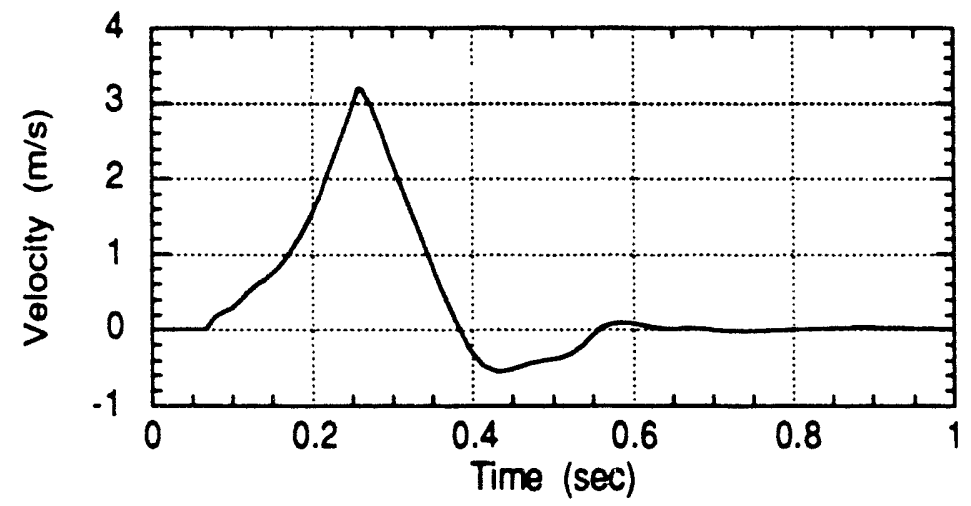

a. Range $=107 \mathrm{~m}$
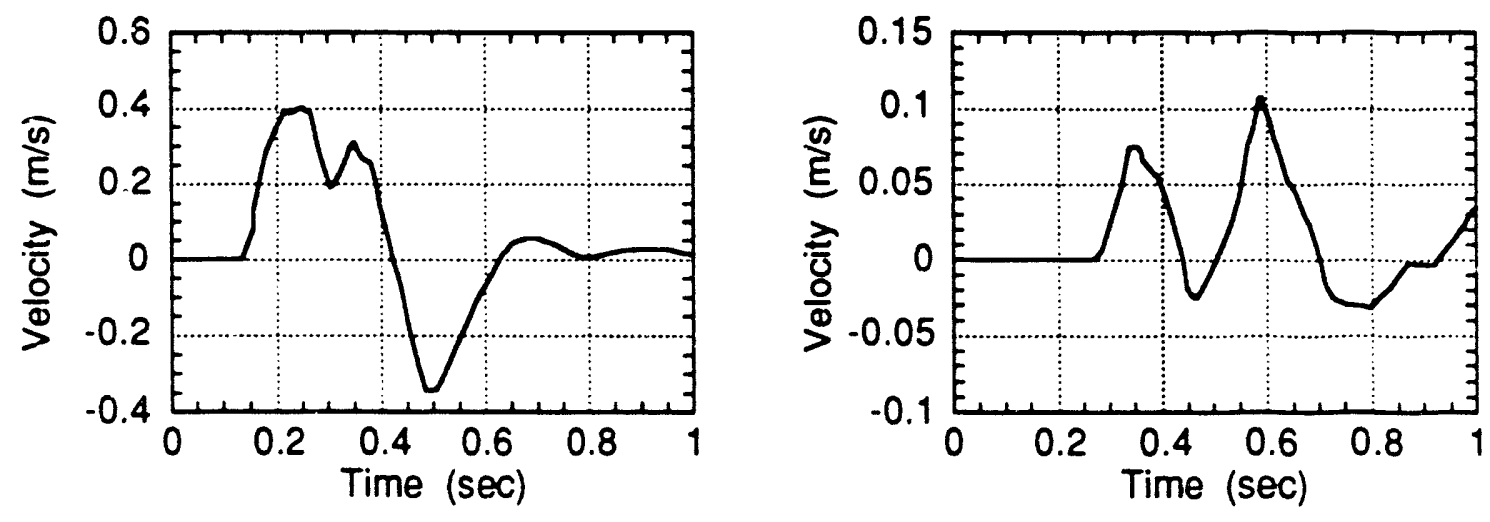

b. Range $=213 \mathrm{~m}$
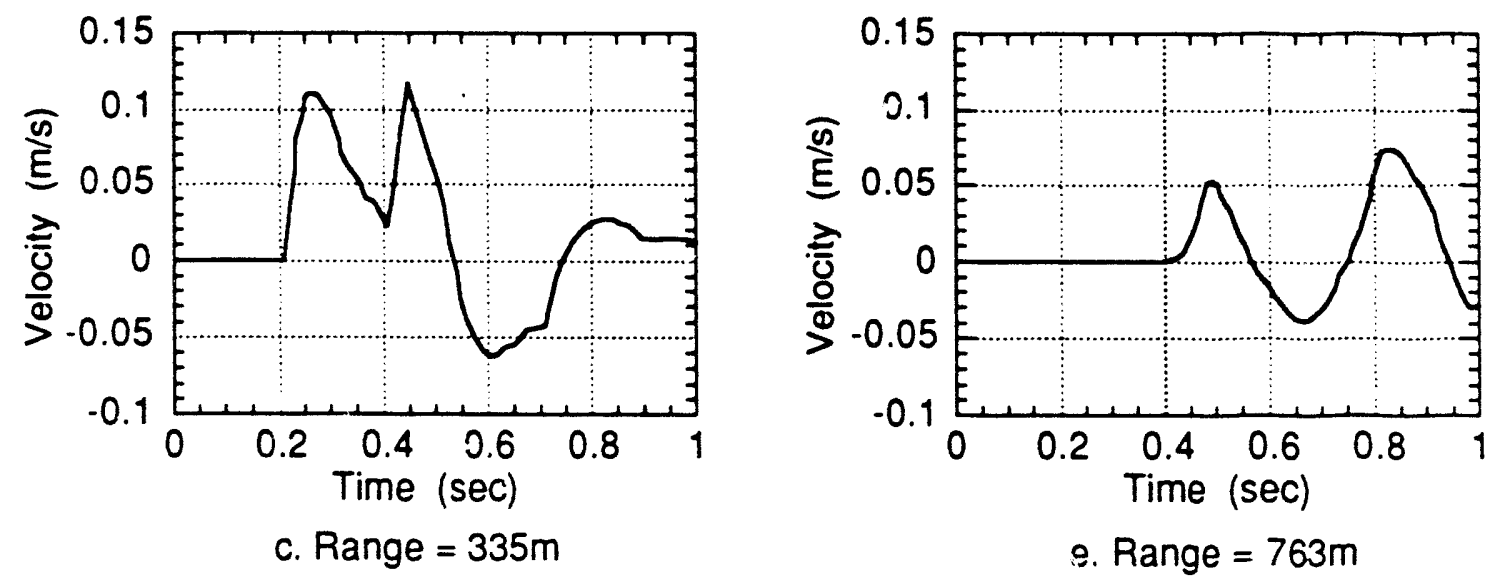

Figure 8. WP-level velocity waveforms for MERLIN event. 


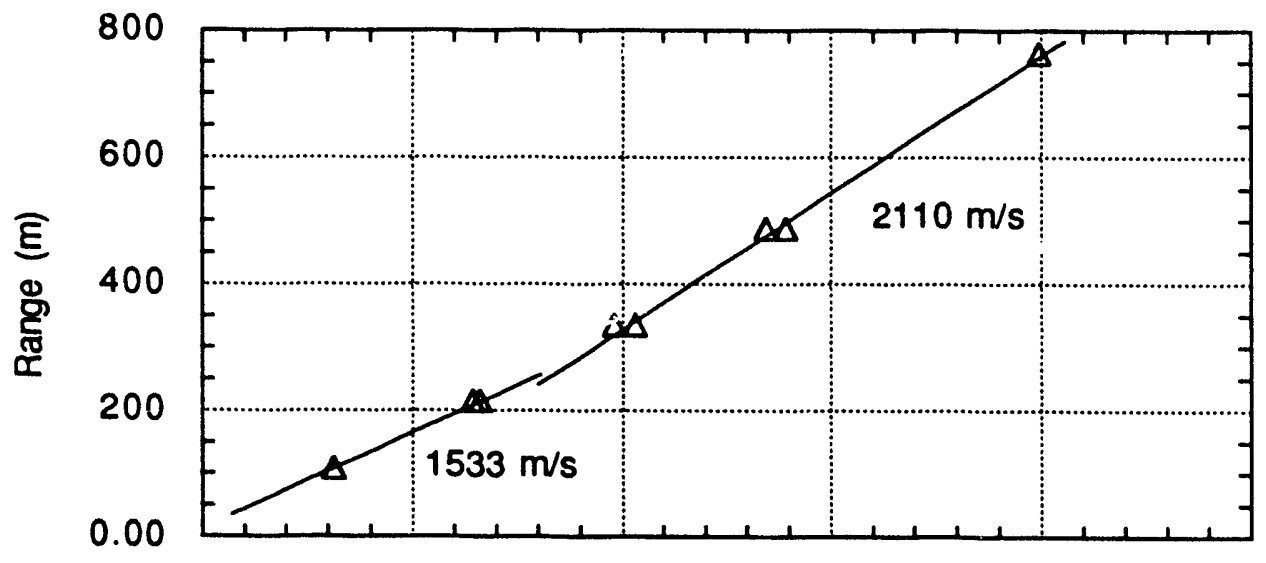

Figure 9. Time-of-arrival for MERLIN WP-level gauges. 


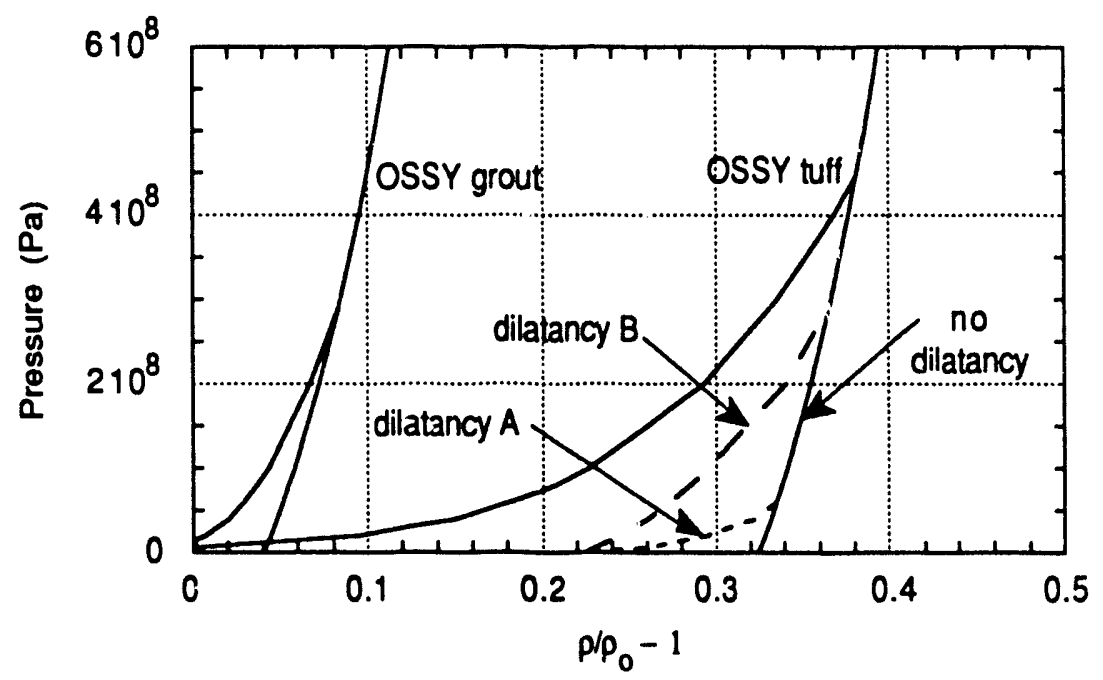

a. Pressure versus excess compression

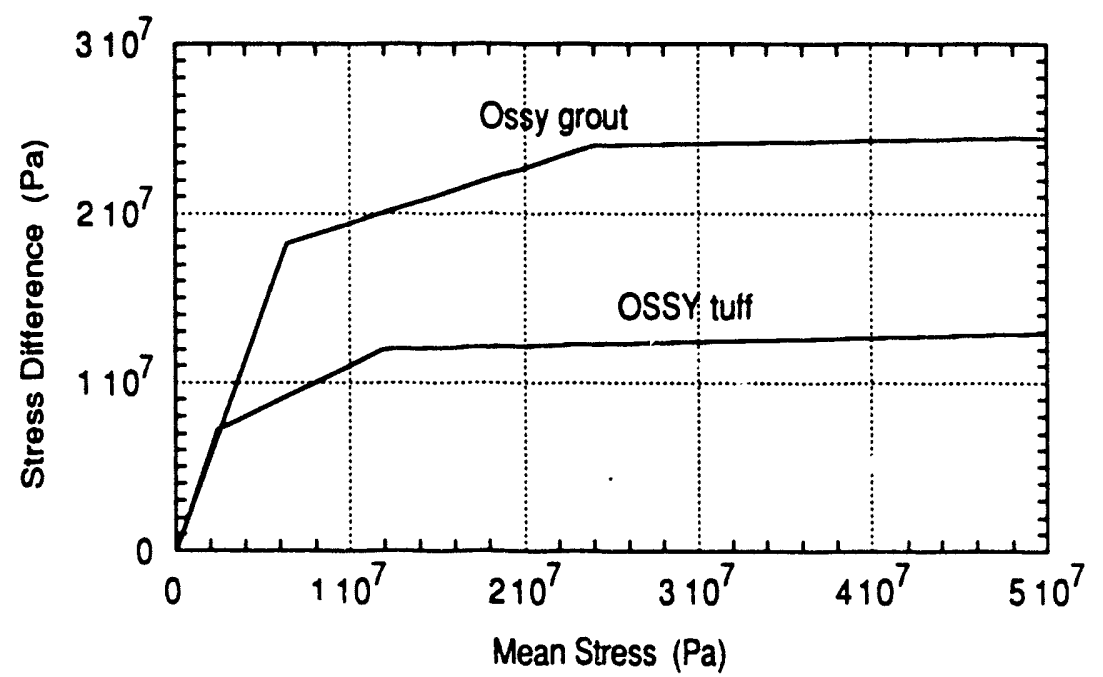

Figure 10. Compression and strength behavior for OSSY calculations. 


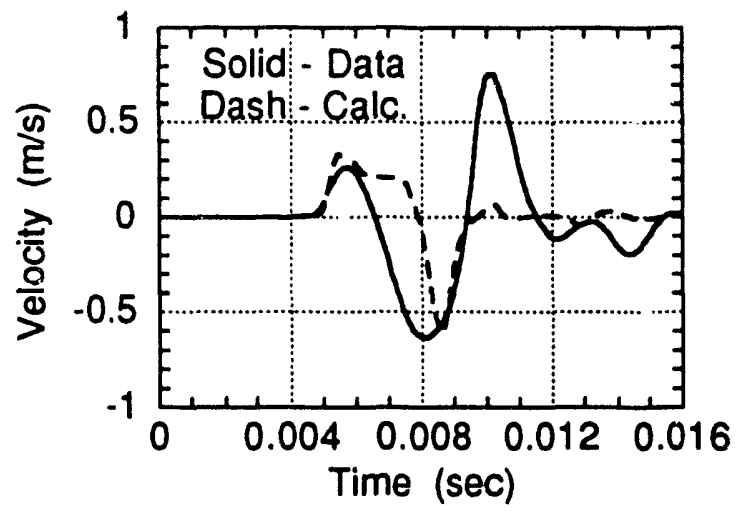

a. Distance $=9.5 \mathrm{~m}$, no dilatancy

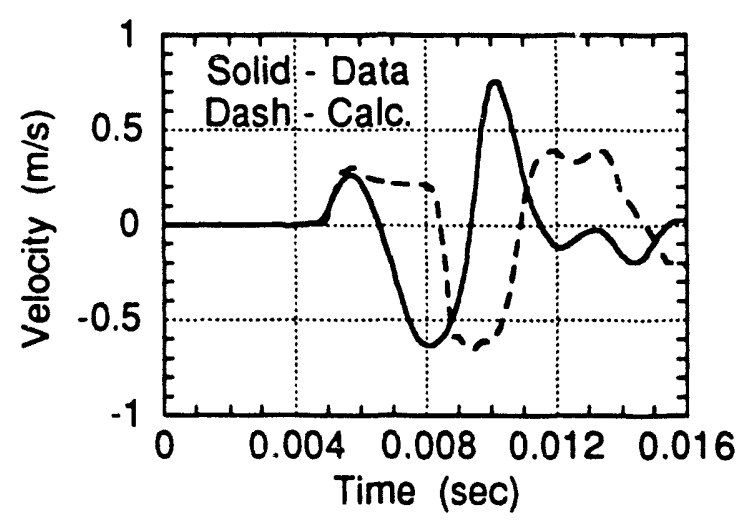

b. Distance $=9.5 \mathrm{~m}$, dilatancy $A$

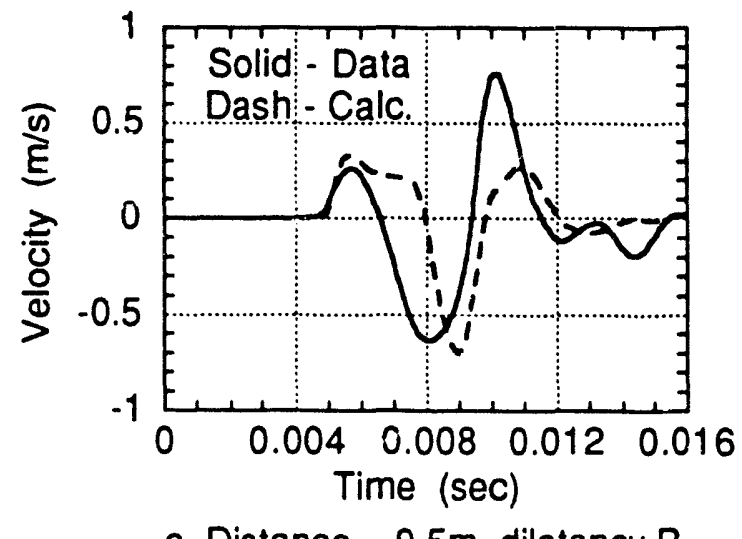

c. Distance $=9.5 \mathrm{~m}$, dilatancy $B$

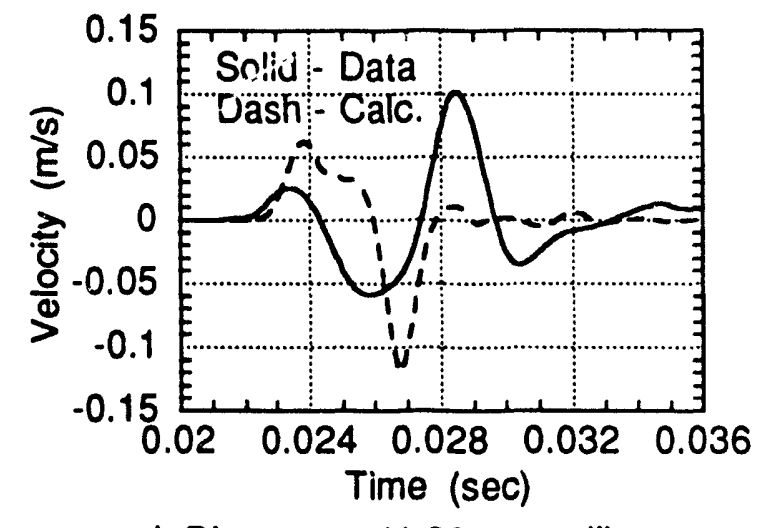

d. Distance $=41.86 \mathrm{~m}$, no dilatancy

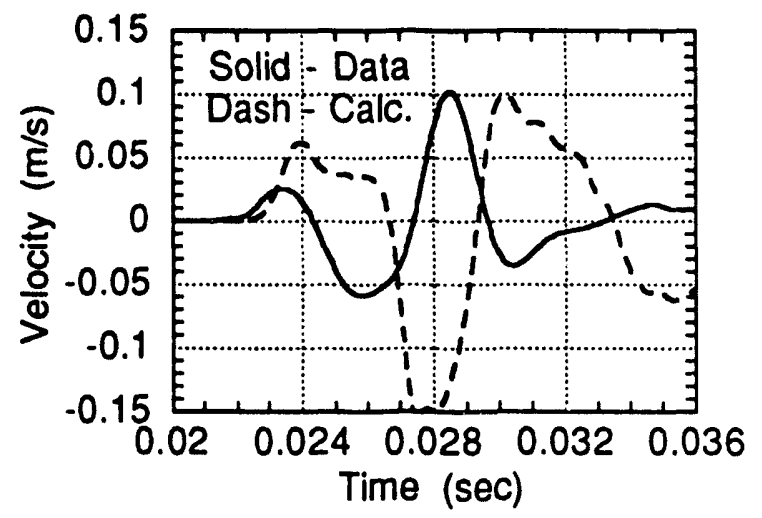

e. Distance $=41.86 \mathrm{~m}$, dilatancy $A$

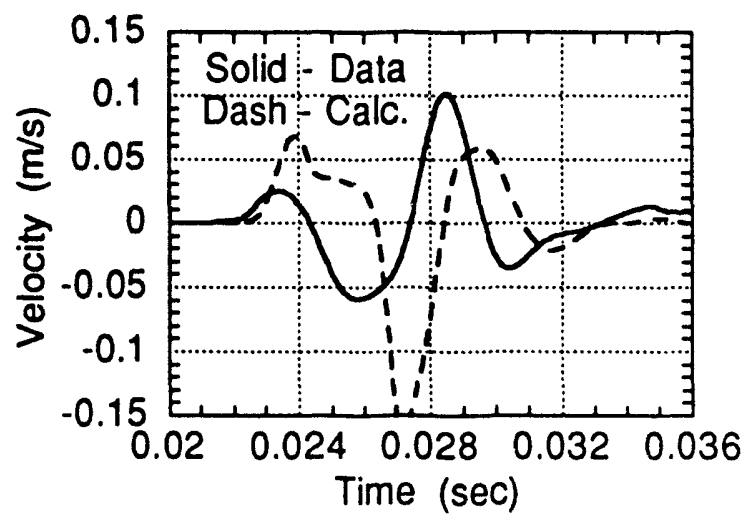

f. Distance $=41.86 \mathrm{~m}$, dilatancy $B$

Figure 11. 1D calculations compared to OSSY data from shot 12 at $9.5 \mathrm{~m}(\mathrm{a}-\mathrm{c})$ and from shot 10 at $41.86 \mathrm{~m}(\mathrm{e}-\mathrm{f})$. 


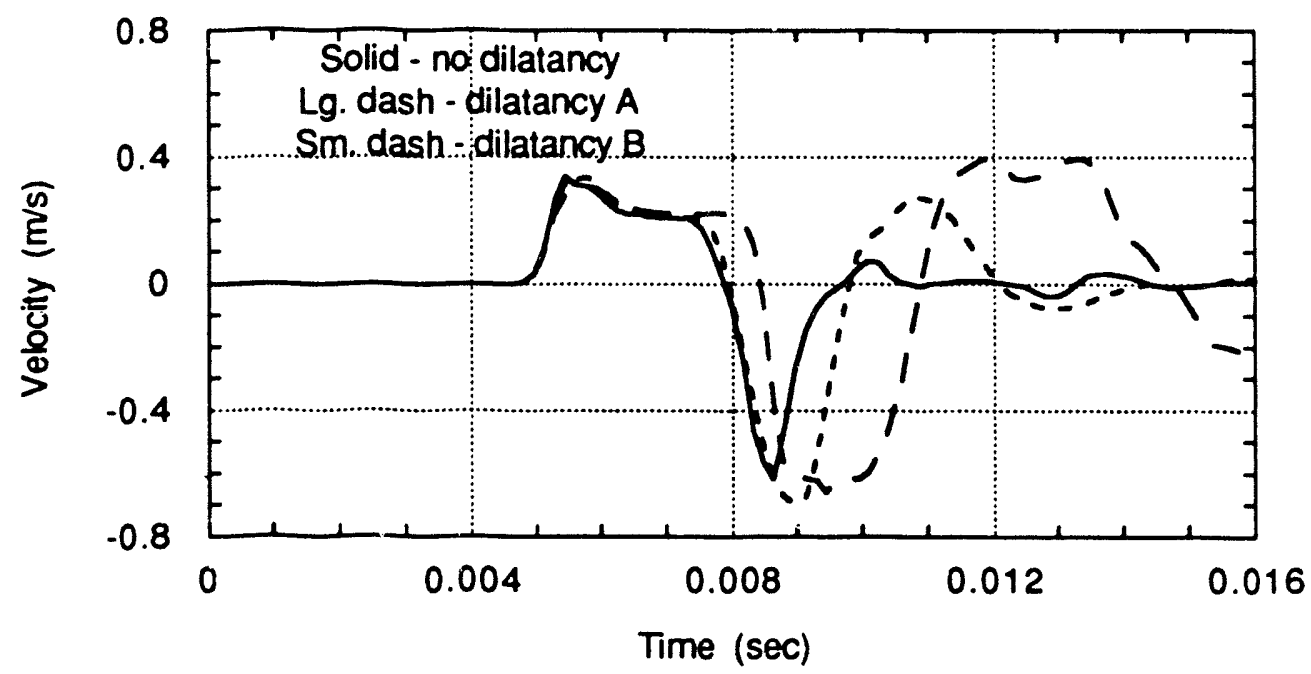

Figure 12. Effect of different dilatant unloading conditions on the calculated OSSY response at $9.5 \mathrm{~m}$.

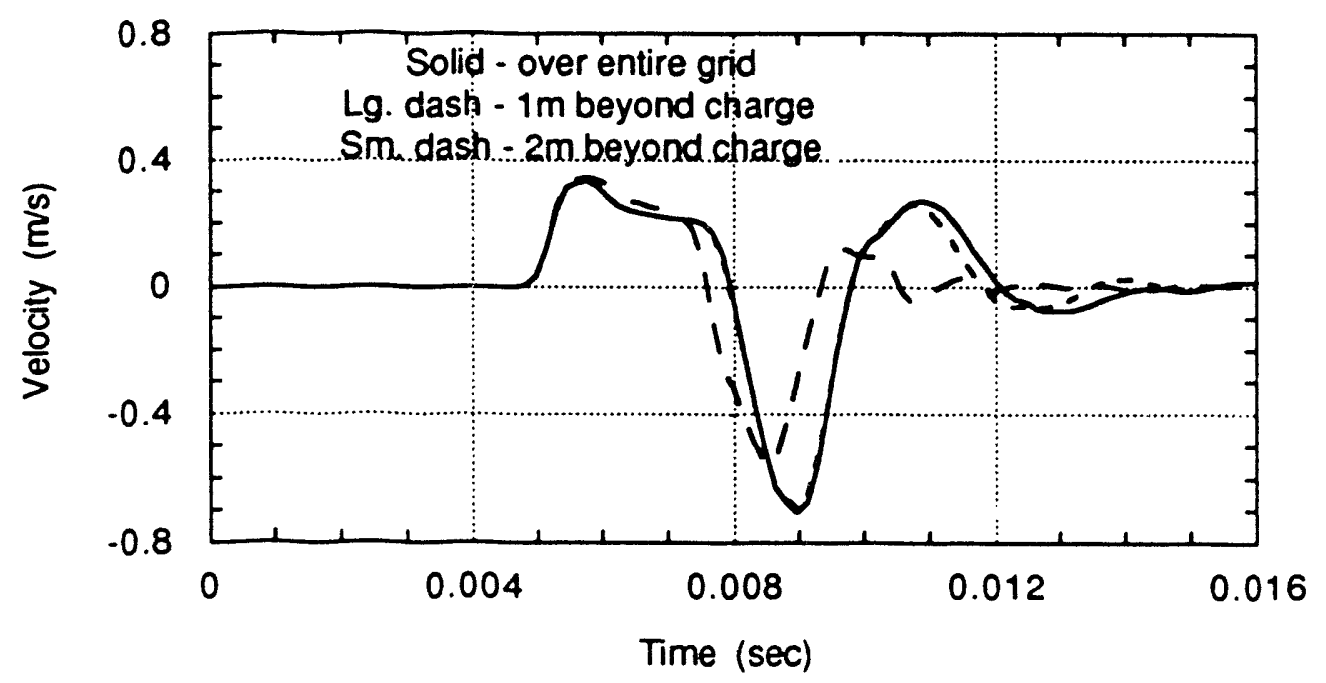

Figure 13. Effect of distance from charge over which dilatancy $B$ acts on the calculated OSSY response at $9.5 \mathrm{~m}$. 


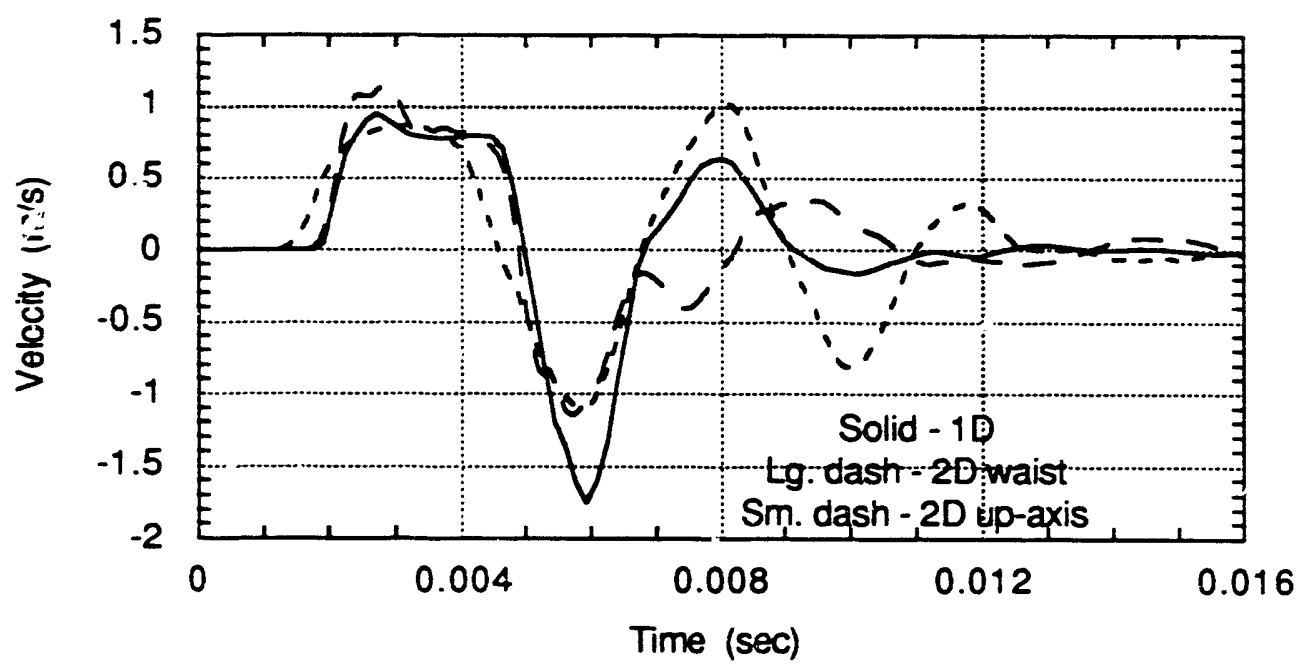

a. Distance $=4 \mathrm{~m}$

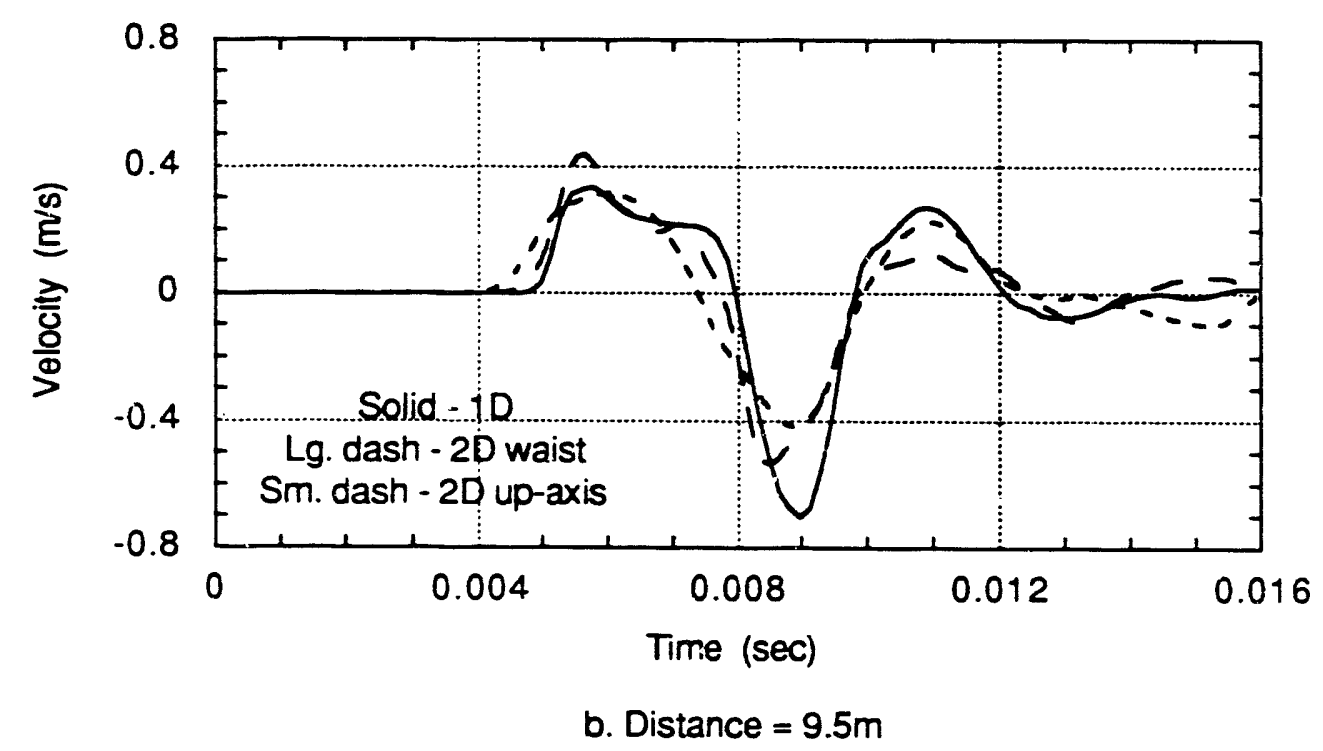

Figure 14. Comparison of calculated $2 D$ up-axis and waist response in uniform geology with grout in wellbore and dilatancy $B$ unloading for tuff with calculated 10 response. 


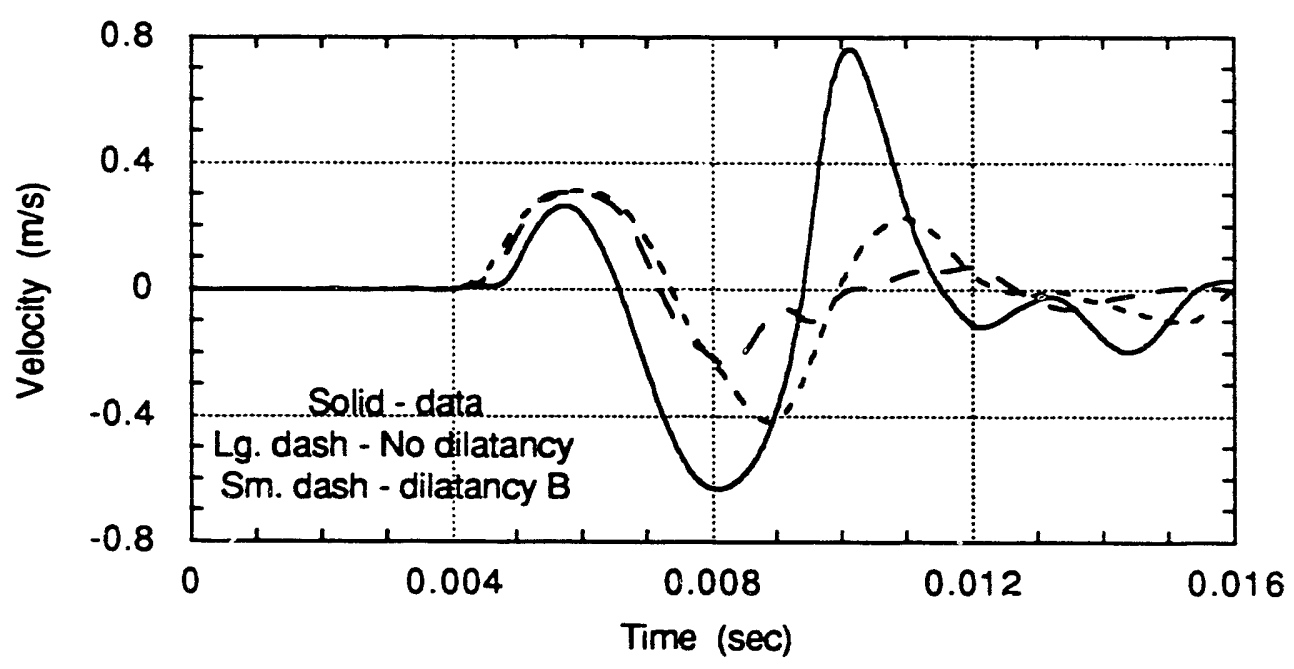

a. Distance $=9.5 \mathrm{~m}$

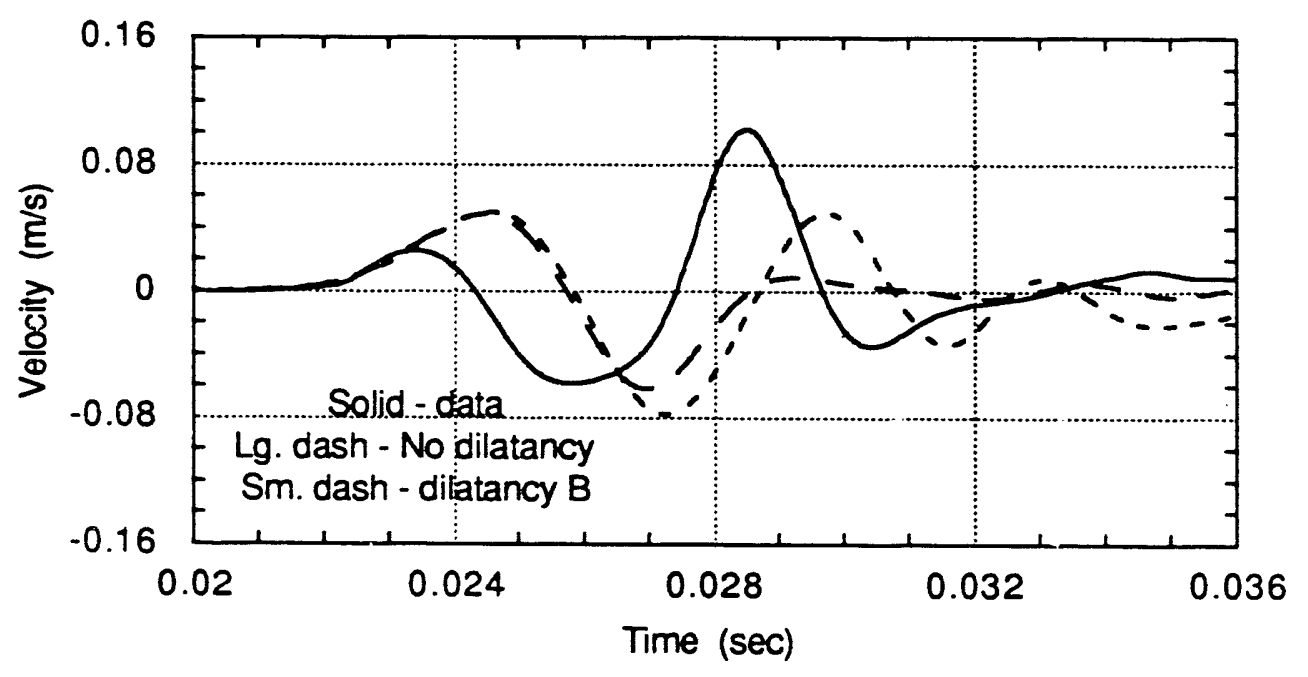

b. Distance $=41.86 \mathrm{~m}$

Figure 15. Calculated 2D up-axis response in uniform geology with and without dilatancy $B$ and with grout in wellbore compared to OSSY data. 

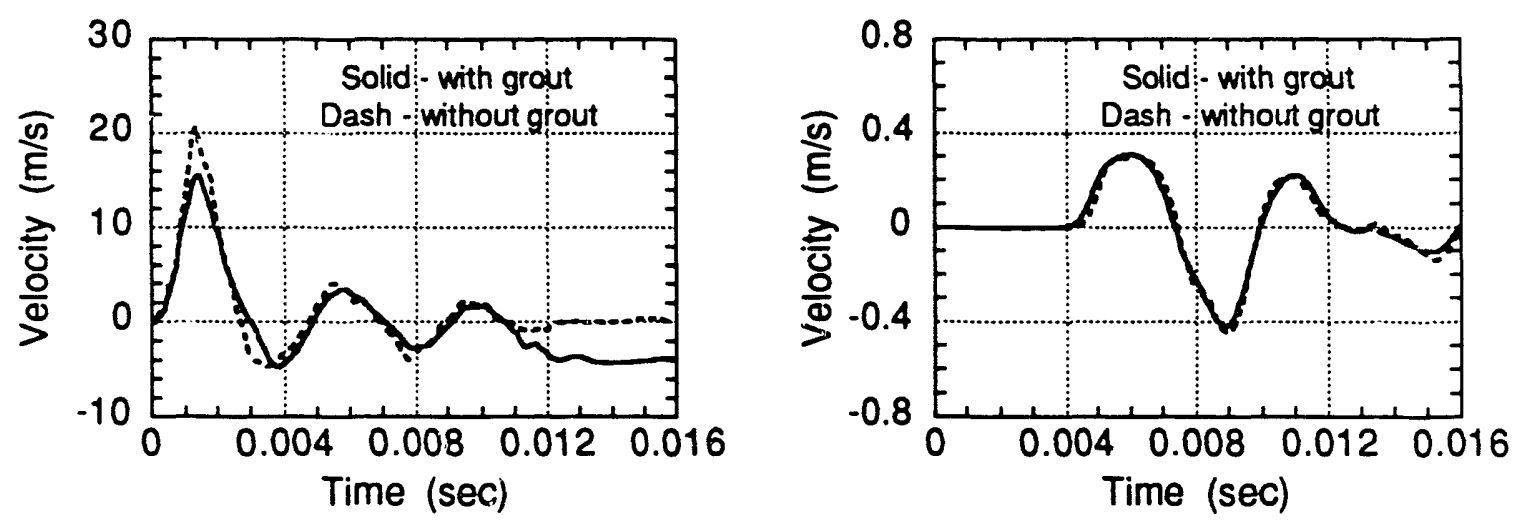

a. Up-axis response at $1.36 \mathrm{~m}$

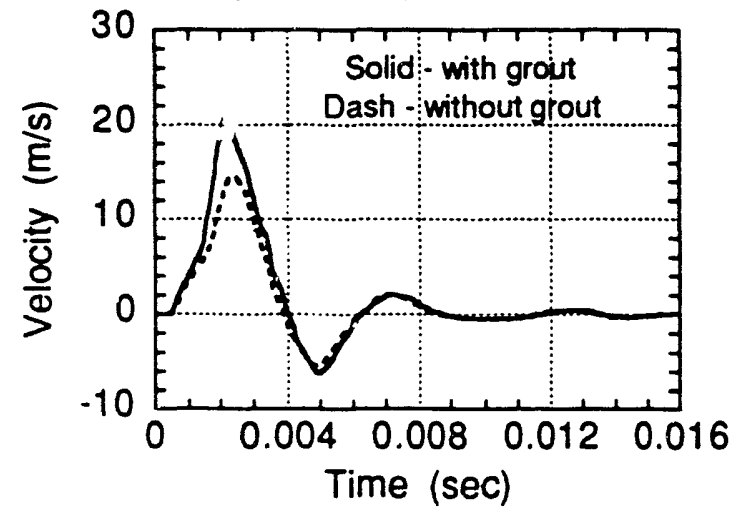

b. Waist response at $1.36 \mathrm{~m}$

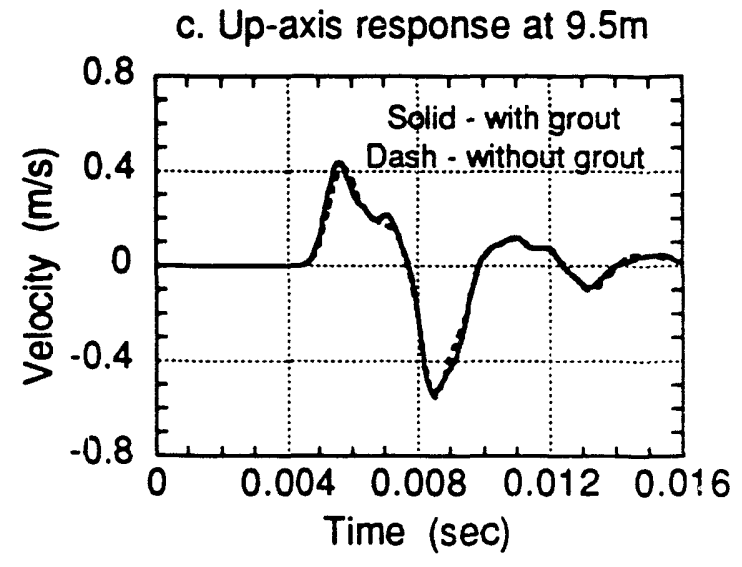

d. Waist response at $9.5 \mathrm{~m}$

Figure 16. Influence of grout emplacement on up-axis response and waist response at distances of $1.36 \mathrm{~m}$ and $9.5 \mathrm{~m}$.

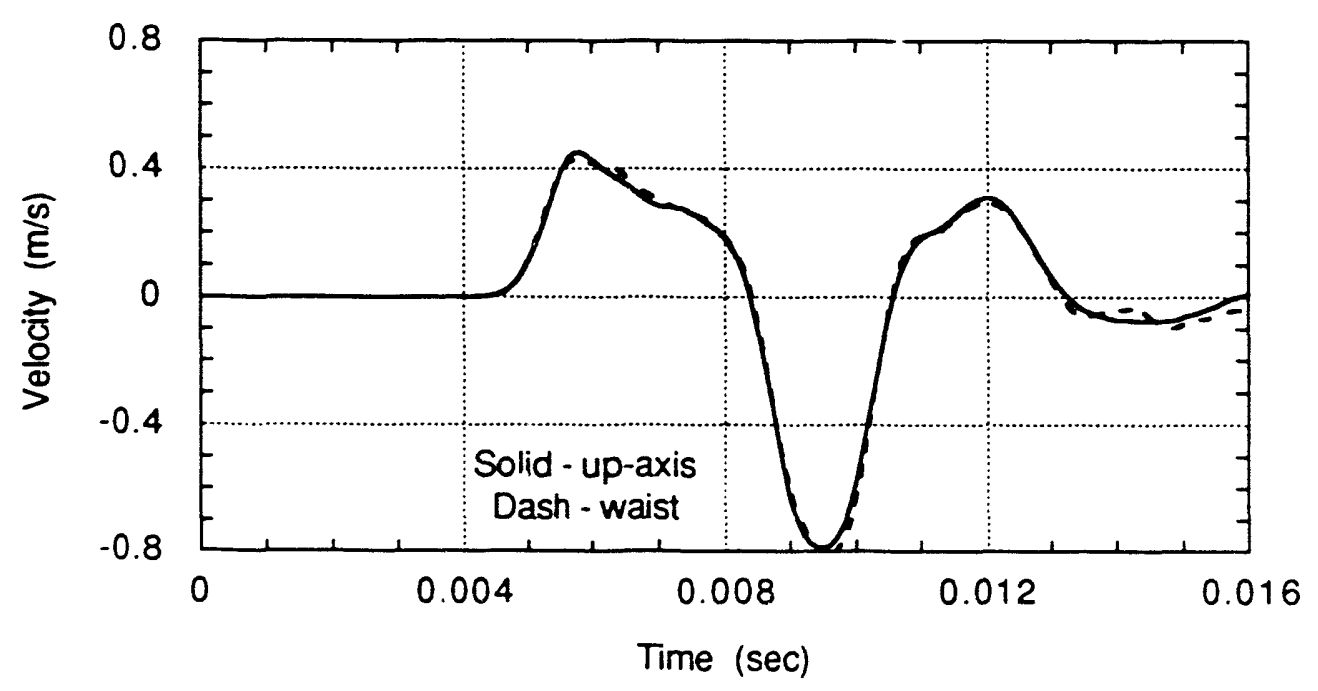

Figure 17. Comparison of calculated up-axis response to waist response for a charge with a one-to-one length-to-diameter ratio. 


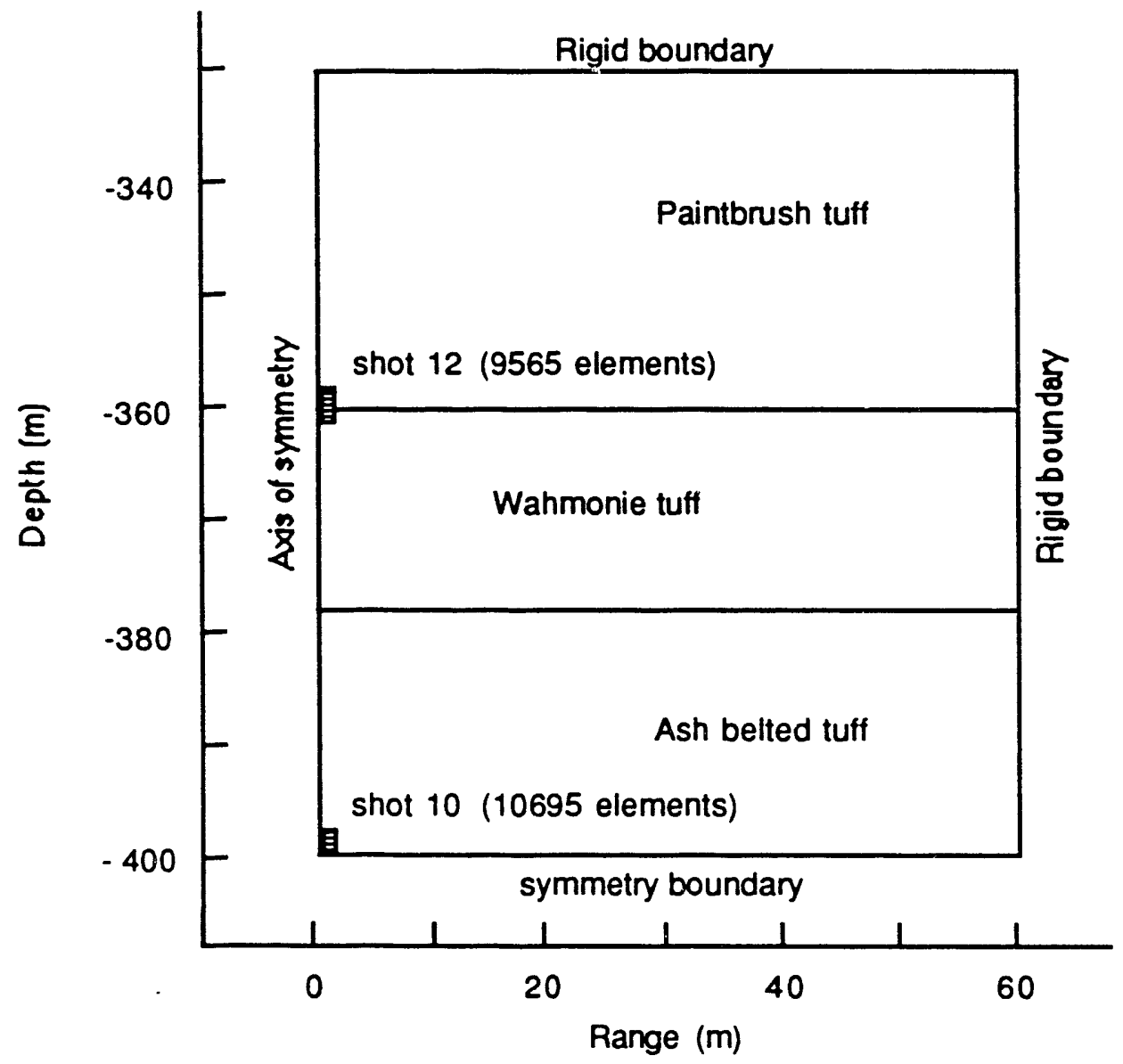

Figure 18. Configuration for 2D OSSY simulations in layered geology. 


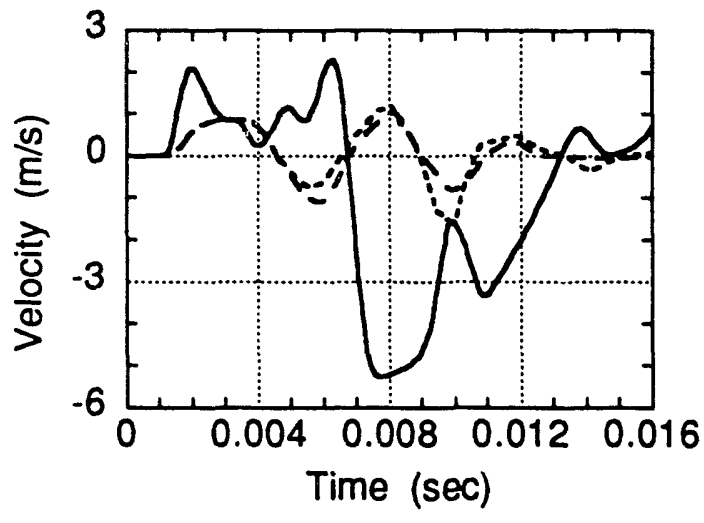

a. Up-axis response at $4 \mathrm{~m}$

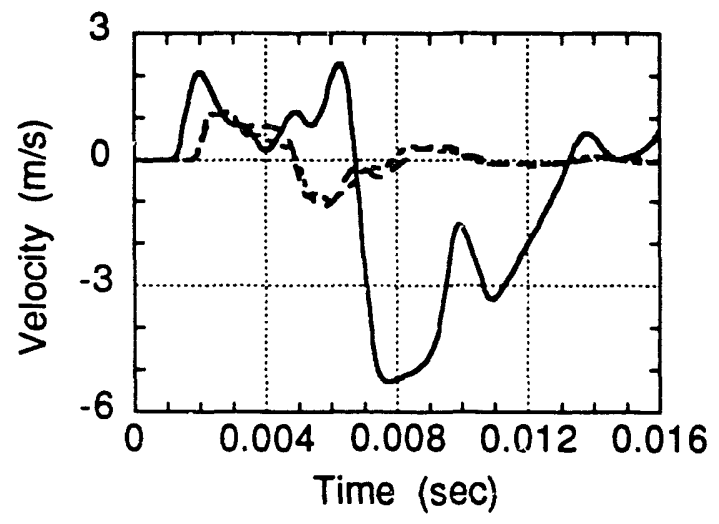

b. Waist response at $4 \mathrm{~m}$

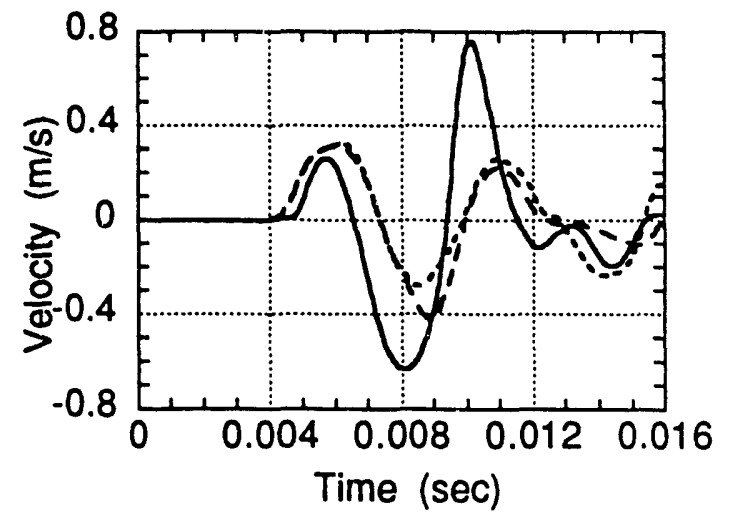

c. Up-axis response at $9.5 \mathrm{~m}$

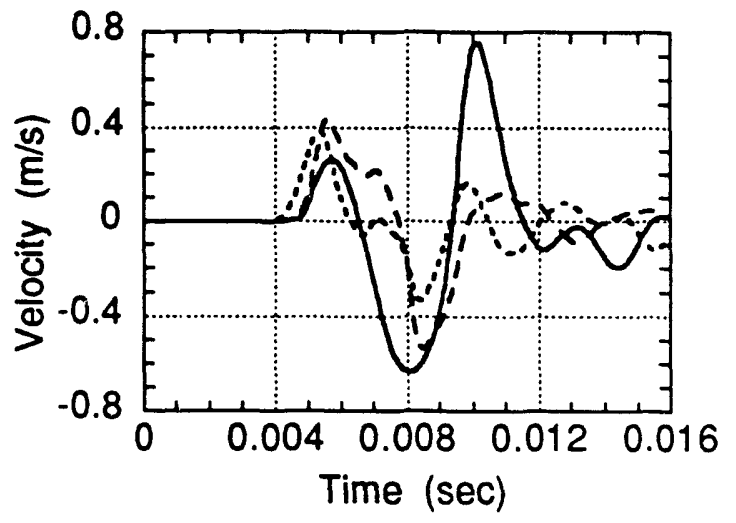

d. Waist response at $9.5 \mathrm{~m}$

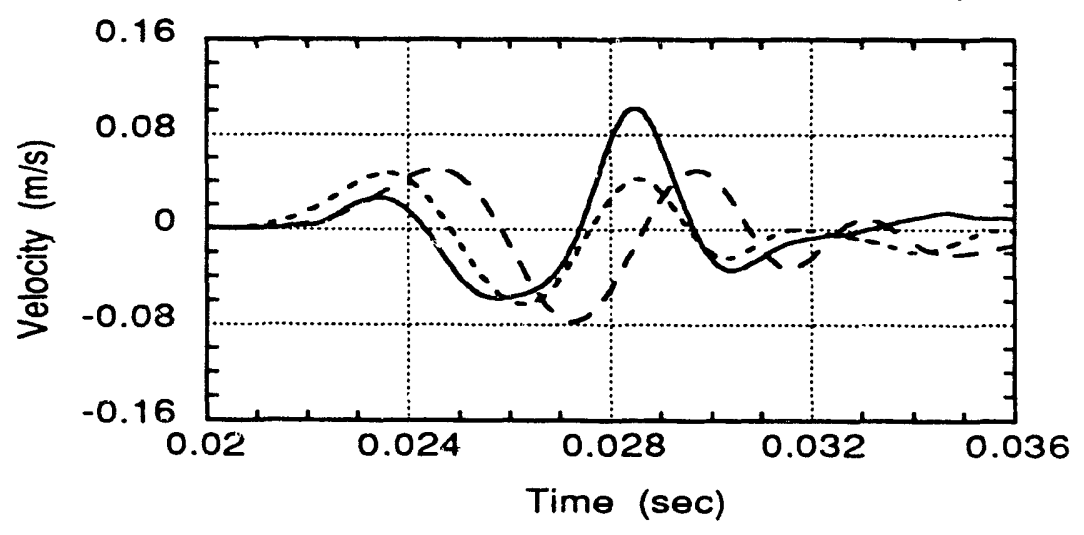

e. Up-axis response at $41.86 \mathrm{~m}$

Figure 19. Comparison of 2D calculated up-axis and waist response for uniform geology (large dash) and layered geology (small dash) with OSSY response data at $4 \mathrm{~m}, 9.5 \mathrm{~m}$, and $41.86 \mathrm{~m}$. 


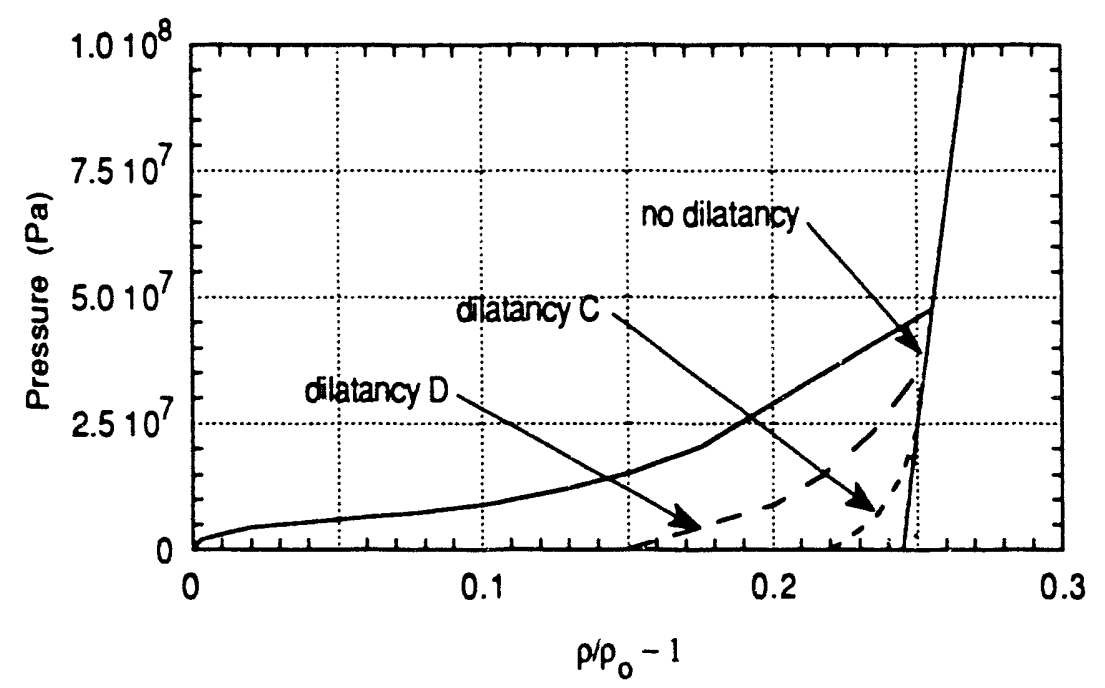

a. Pressure versus excess compression

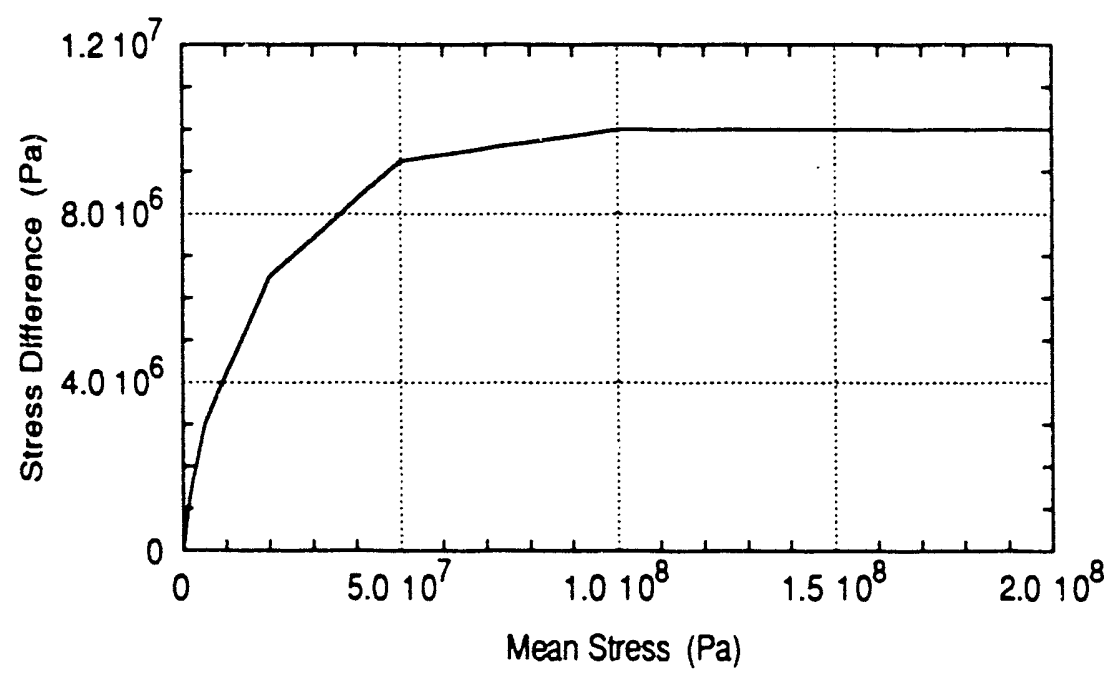

b. Shear strength versus mean stress

Figure 20. Compression and strength behavior for MERLIN alluvium. 


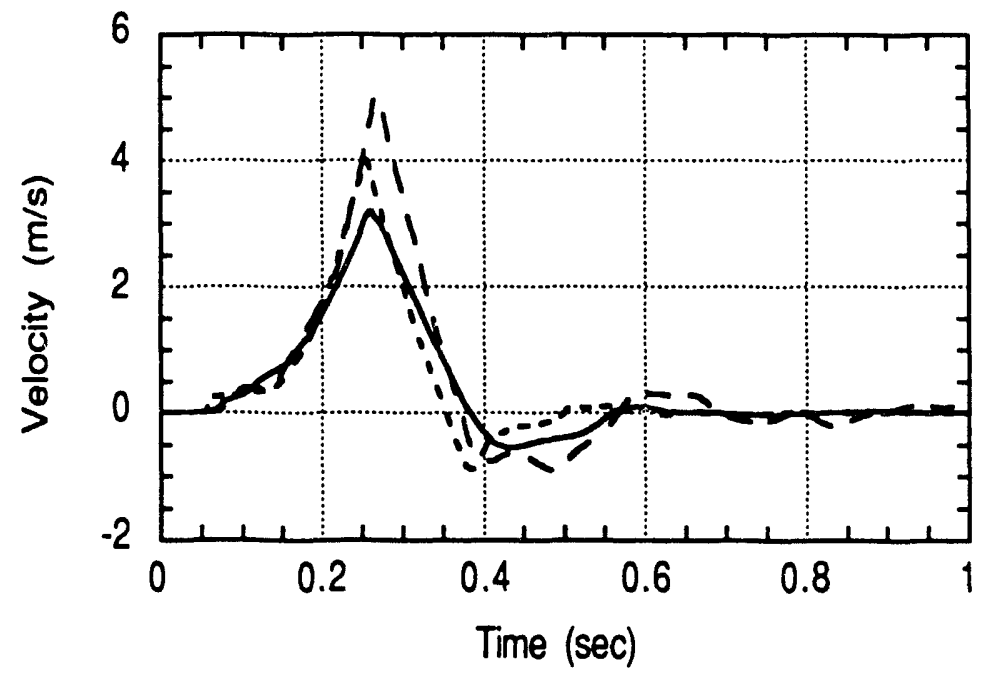

a. Range $=107 \mathrm{~m}$
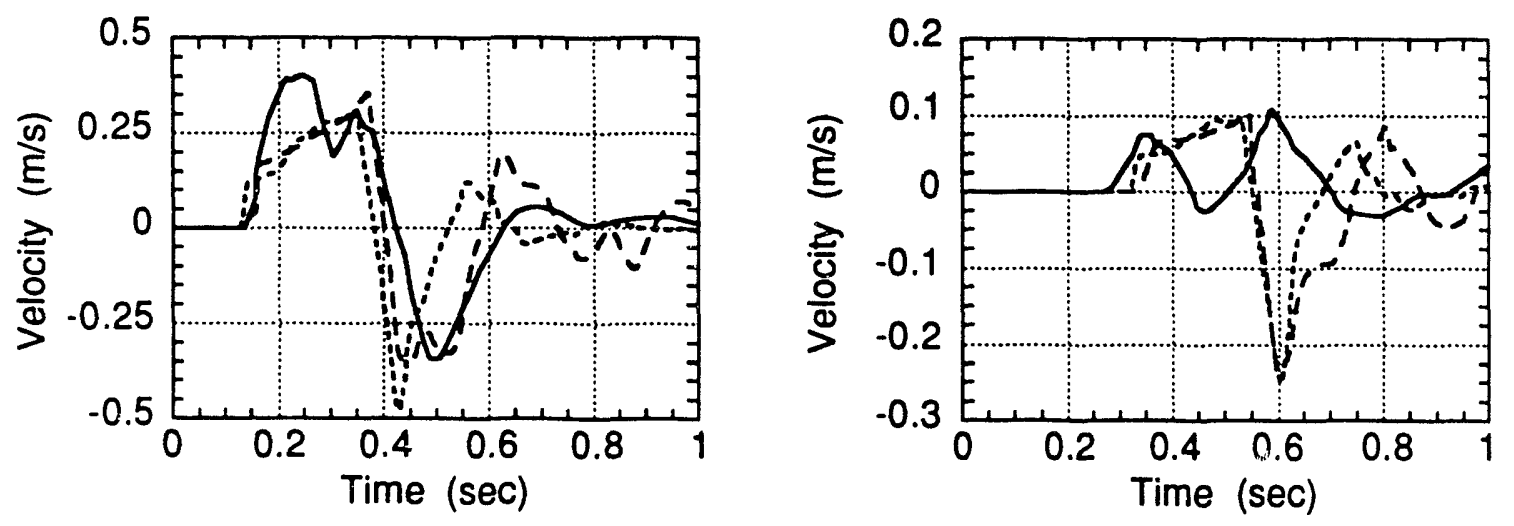

b. Range $=213 \mathrm{~m}$
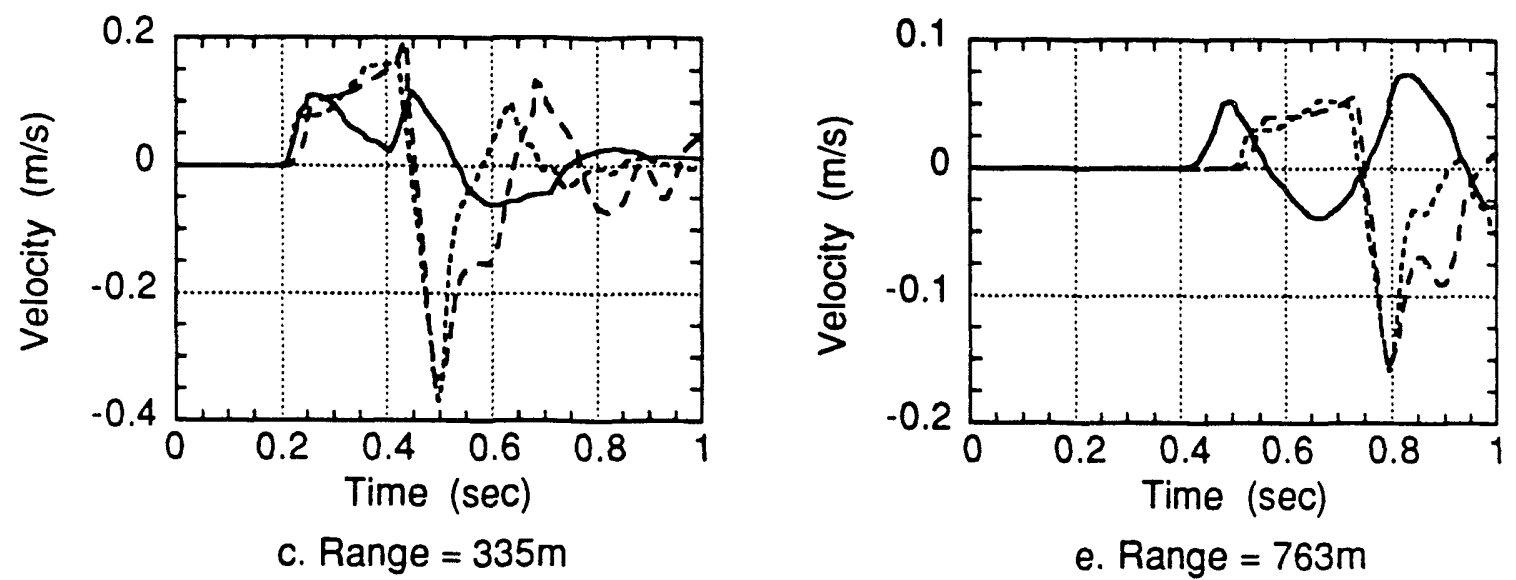

Figure 21. Comparison of $1 \mathrm{D}$ calculated response with dilatancy $D$ (large dash) and without dilatancy (small dash) to MERLIN data (solid line) at WP-level stations. 


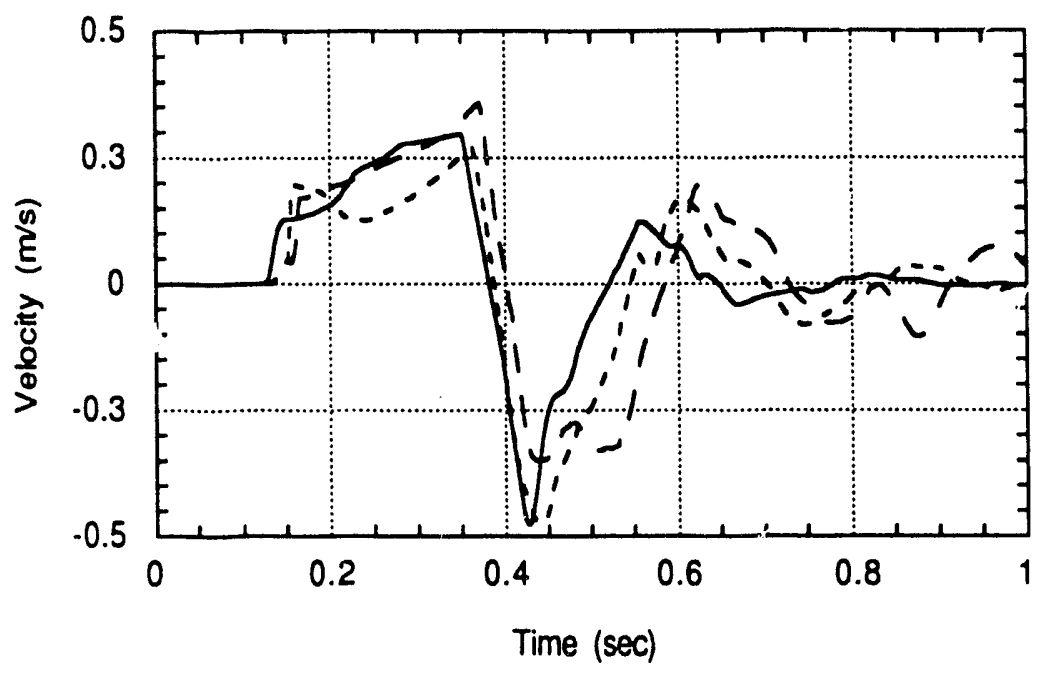

a. Range $=213 \mathrm{~m}$

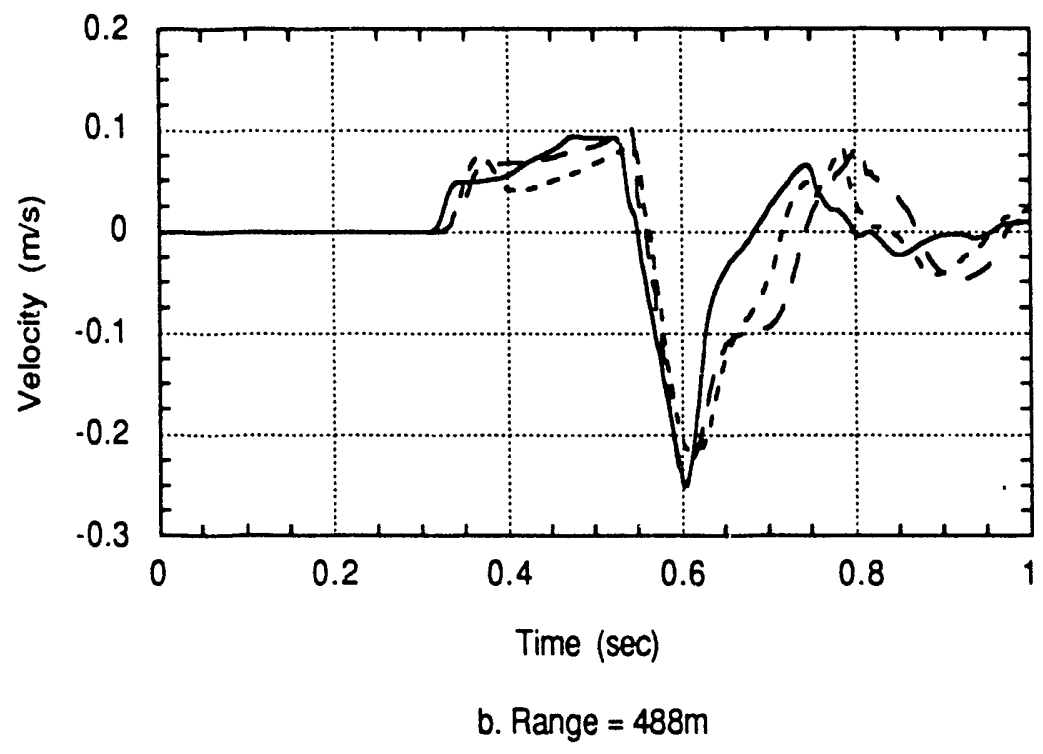

Figure 22. Effect of different dilatant unloading conditions on the 1D calculated MERLIN response. No dilatancy (solid line), dilatancy C (small dash), and dilatancy D (large dash). 


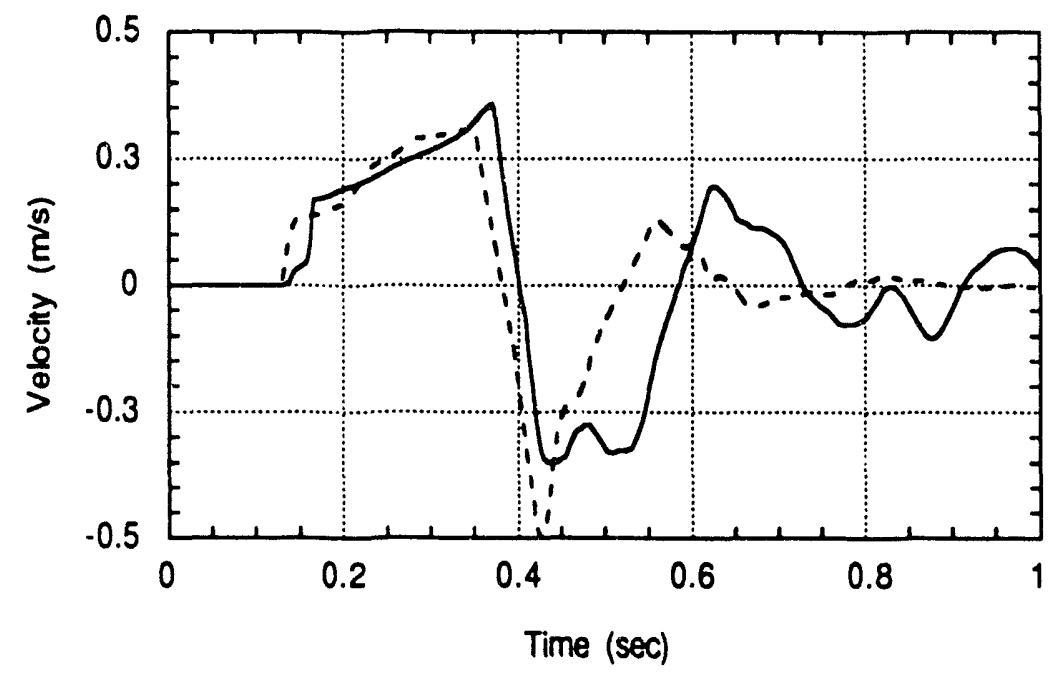

a. Range $=213 \mathrm{~m}$

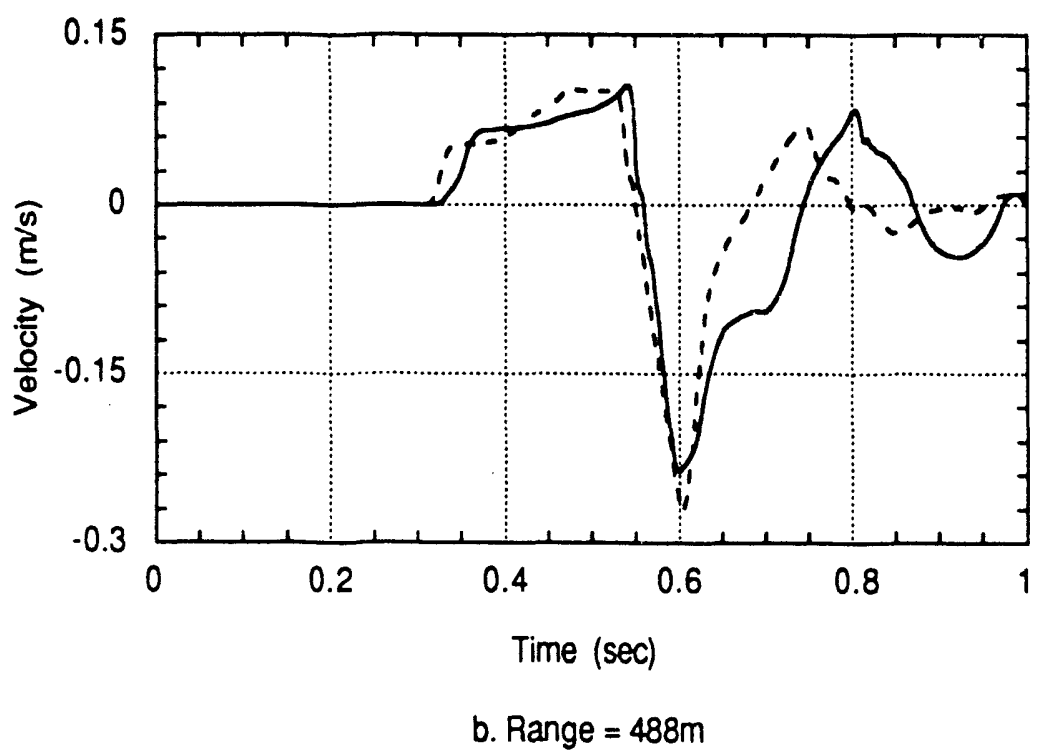

Figure 23. Comparison of 1D calculated response showing effect of dilatancy $D$ confined to within 100 meters from source (dash line) to that acting over the entire grid (solid line). 


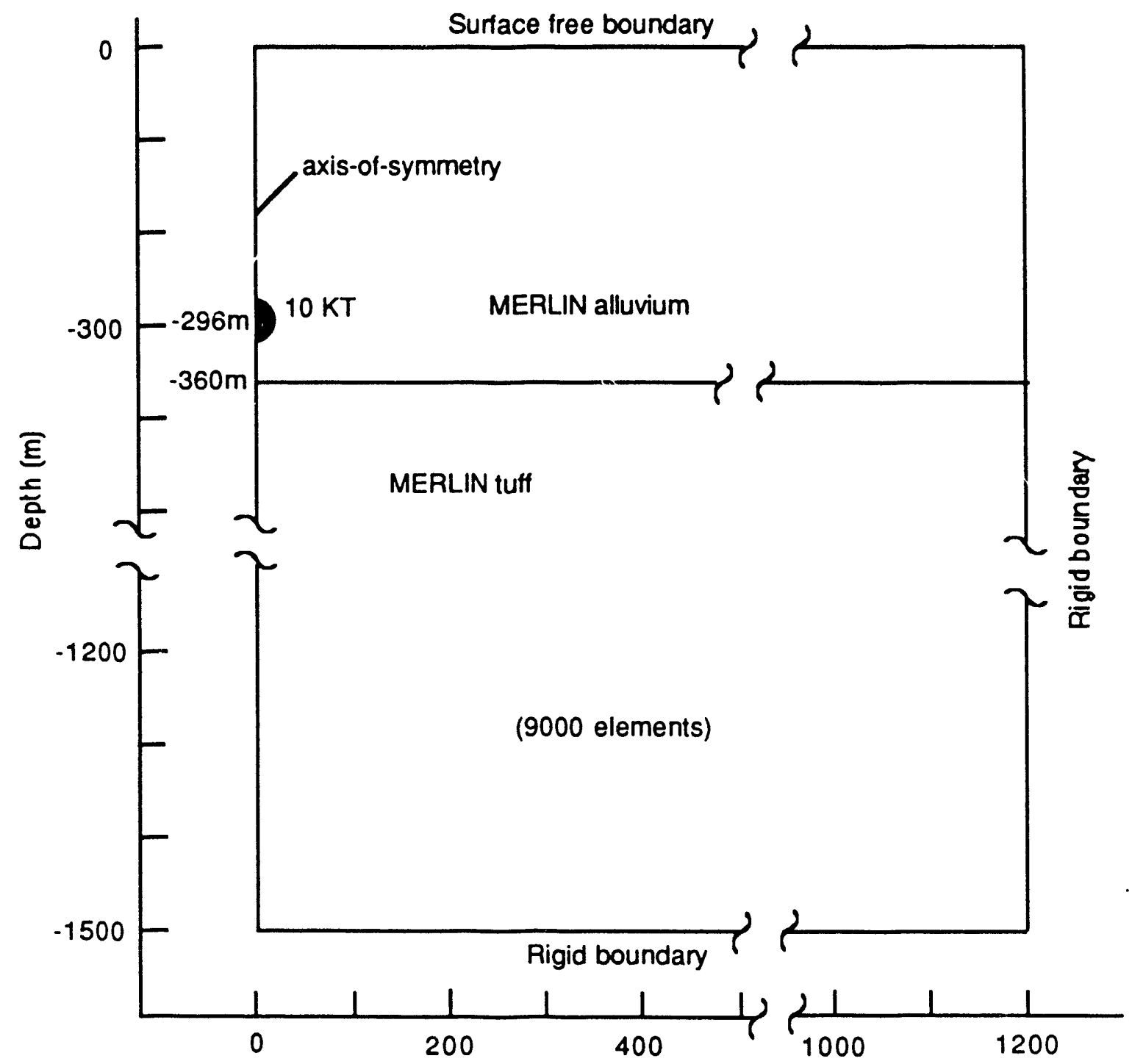

Figure 24. Configuration for $2 D$ simulations of the MERLIN event. 


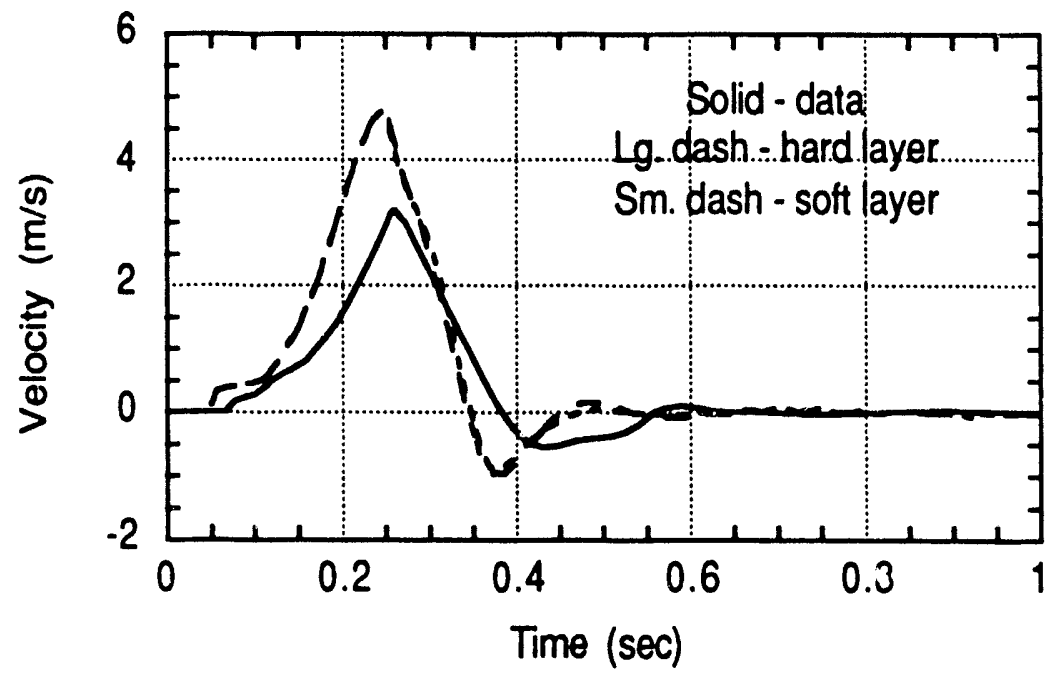

a. Range $=107 \mathrm{~m}$

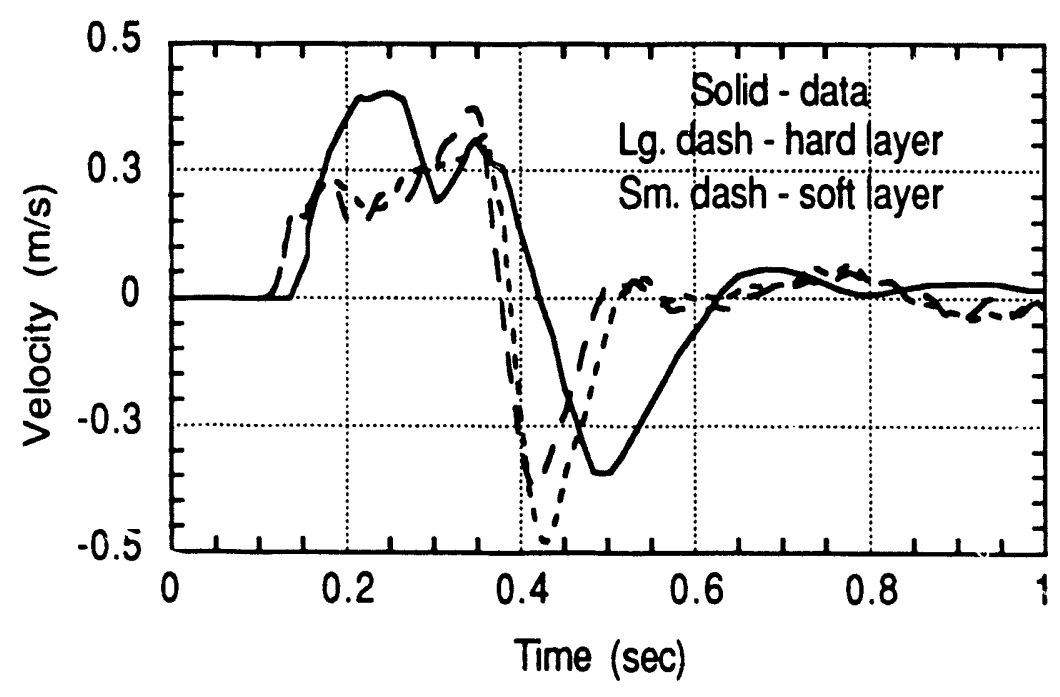

b. Range $=213 \mathrm{~m}$

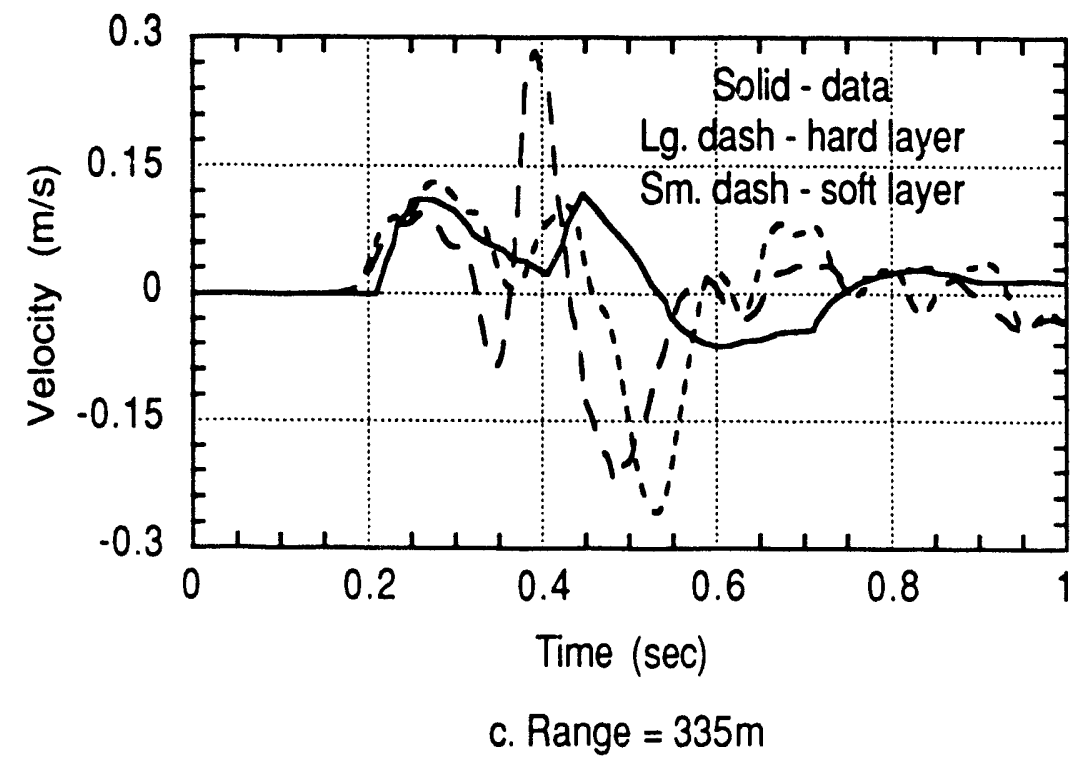



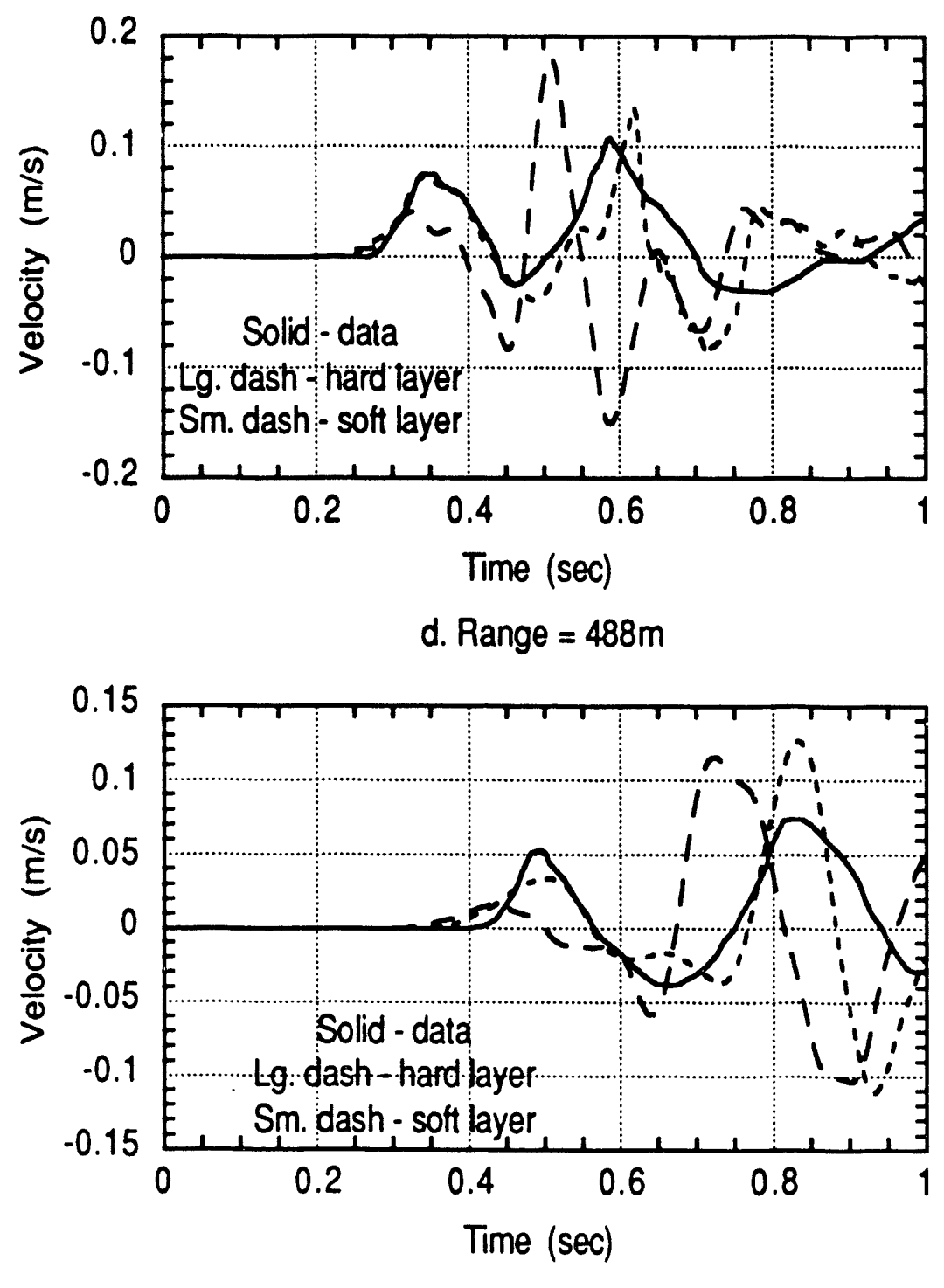

e. Range $=763 \mathrm{~m}$

Figure 25. Comparison of 2D calculated response with a hard layer (large dash) and a soft layer (small dash) located 60 meters below WP-level to the MERLIN response at WP-level (solid line). 


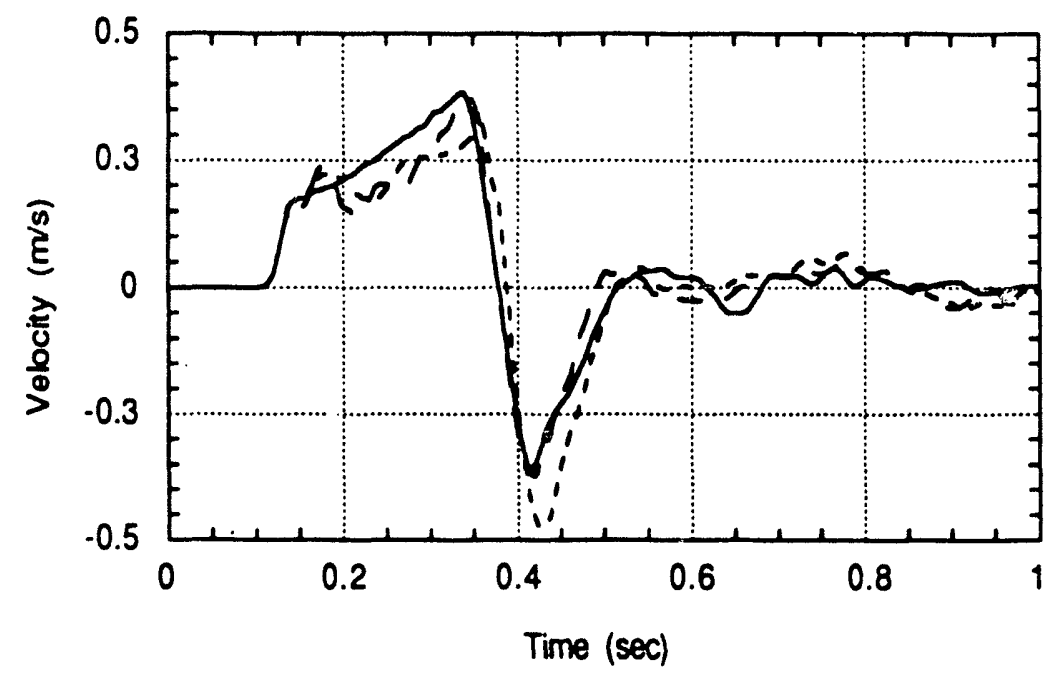

a. Range $=213 \mathrm{~m}$

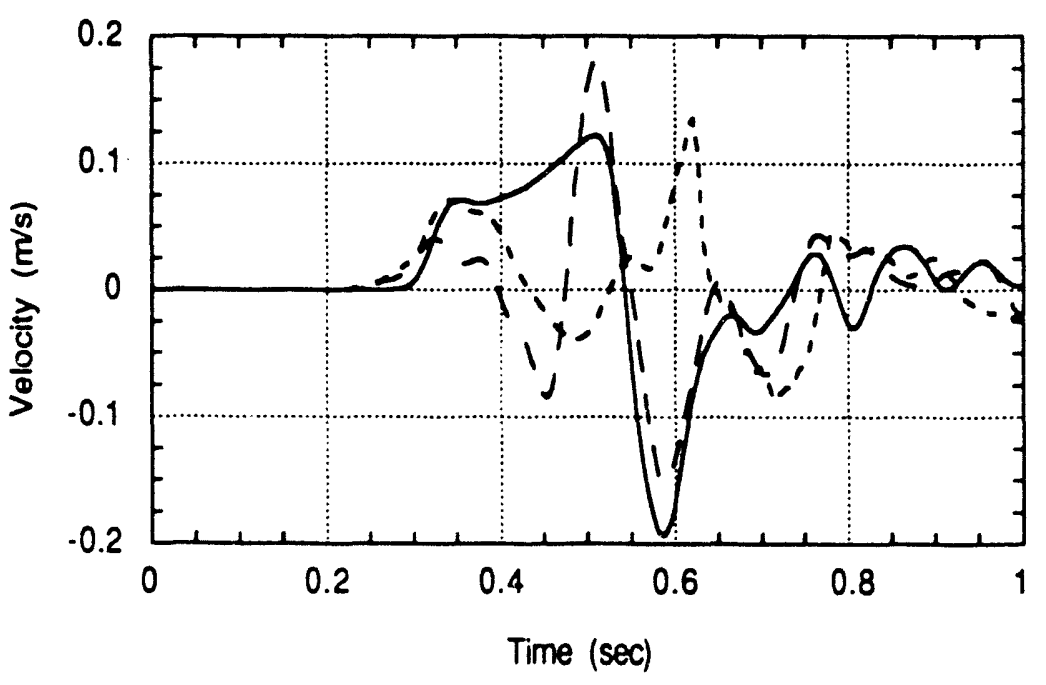

b. Range $=488 \mathrm{~m}$

Figure 26. Comparison of 2D calculated WP-level response for MERLIN in uniform geology (solid line) to cases with a hard layer (large dash) and a soft layer (small dash) located 60 meters below WP-level. 

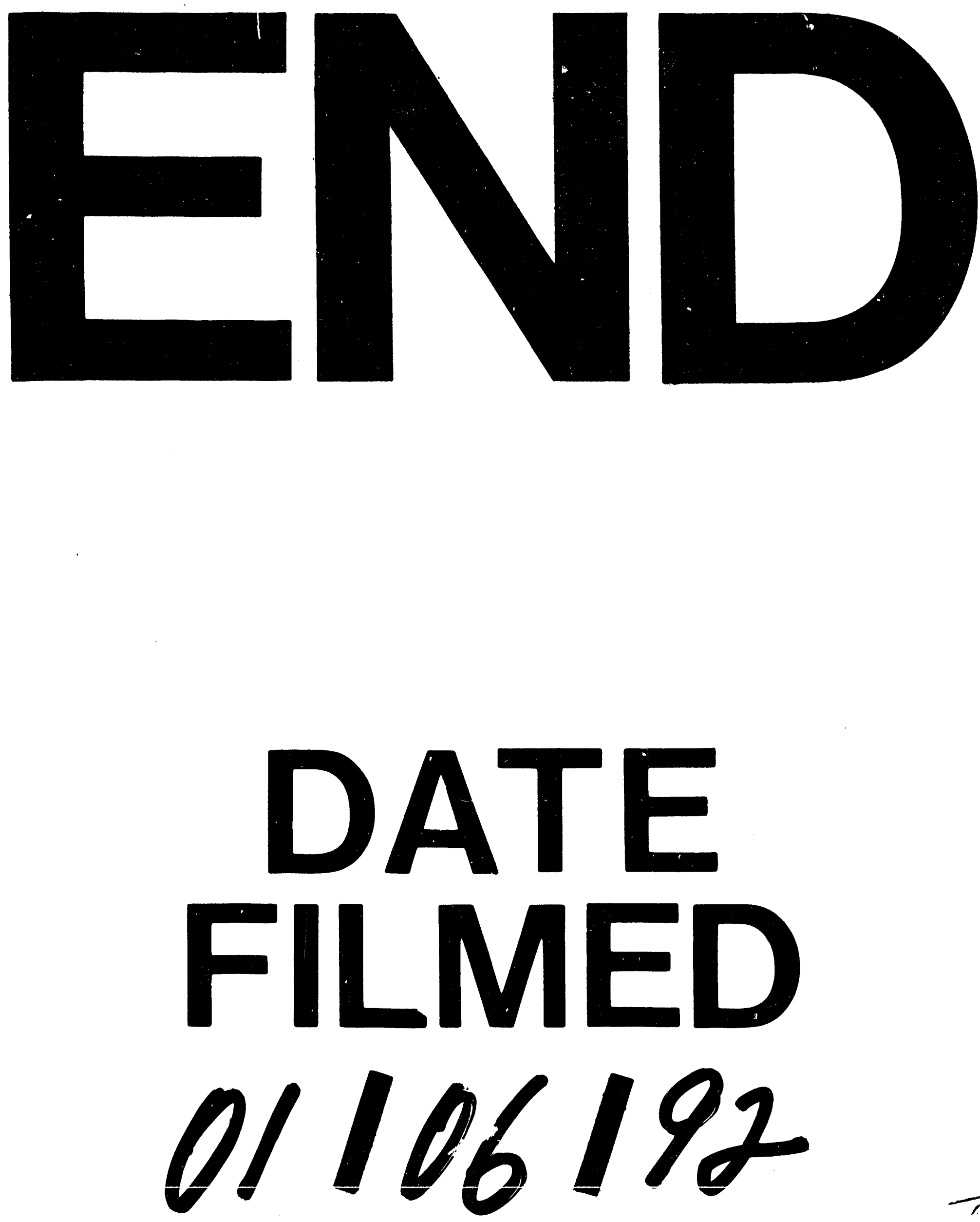